\title{
Evaluation of Some Promising Teosinte Genotypes for Morphological and Genetic Parameters under Egyptian Conditions \\ Hend E. Habiba ${ }^{1}$, Abd El Aziz. T. Bondok ${ }^{1}$ and Mohmed. S. Abdel-Aal ${ }^{2}$
}

\begin{abstract}
This investigation was conducted at Gemmeiza, Agric. Res. Station, El -Gharbia Governorate, Agricultural Research Center (ARC), Egypt, during the period between 2014 and 2015 summer seasons to evaluate eight selected teosinte genotypes. The experimental design was a randomized complete block with three replicates. The data measured were fresh yield (fr) and dry yield (dy) over the consecutive cuts. Plant height (ph), stem dimeter (SD), number of leaves on the main stem (NL), leaf area per plant, dry matter (DM), fresh yield, dry yield, fresh leaves / stem (\%) and dry leaves / stem (\%) and were recorded at cutting time.
\end{abstract}

Heritability estimate, in the broad - sense $\left(h^{2} b\right)$, on mean basis for traits, were carried out. Genotypes 3 and 4 were the superior to the other tested genotypes in morphological characters in both seasons. The heritability was high in fresh yield (fy) $\mathbf{( 9 9 . 9 \% )}$ ) and dry matter (DM) $(\mathbf{9 9 . 8 \%})$, followed by plant height $(\mathbf{9 9 . 5 \%})$ and leaf area (99.5\%).

(SDS - PAGE) official sodium dodecyl sulphate polyacrylamide gel electrophoresis was employed to detect variation in total soluble protein content technique among the eight genotypes of teosinte; namely, 1, 2, 3, 4, , 6, 7 and 8 genotypes. Different protein fragmentation was recorded for the teosinte genotypes, which ranged from 21 to 16 for $1,2,3$ and 4 genotypes repectively, with molecular weight (MW) ranged from 154 to $7 \mathrm{kda}$. It was found that similarity and dissimilarity, for protein patterns of teosinte genotypes, showed that 3 and 4 genotypes showed the same protein patterns, with almost protein loci and molecular weights, with 18 and 16 protein bands. According to electrophoretic study. Phyllogenetic tree was constructed and indicated a clear genetic base from SDS - PAGE analysis, high similarity percentage i.e. $(94.5 \%)$ for genotype 3 , and the lowest similarity percentage $(\mathbf{7 6 . 2 \%})$ for the fist genotype.

The genotypes were divided into three main groups; i.e., the genotypes $(1,8)$, were in one group, while genotype (2) was in the second group and $(3,4,5,6$ and 7$)$ genotypes were in third group.

Key words : Teosinte, genotypic, evaluation, SDS PAGE and heritability in broad sense.

\section{INTRODUCTION}

Teosinte (Zea Mexicana (Schrad); 2n = 20, originated in Mexico) is grown in the summer season as a multi - cut forage crop (Fedoror, 1974). It is a promising forage summer crop in Egypt, which needs more research to introduce it to farmers and producers. Dewet et. al. (1971) assumed that Zea Mexicana (teosinte) originated from natural hybridization of Zea mays (Maize) with a species of Tripsacum. They showed that most modern races of maize resulted from introgression of primitive maize. With teosinte and tripsacum, or both. The assumption that teosinte originated as a hybrid between domesticated Zea mays and a species of Tripsacum by backcrossing remains an intriguing possibility (Aulicin and Magoja, 1991).

All species of teosinte, closely, resemble maize, with staminate flowers borne in tassels and pistillate flowers in axillary spikes. Teosinte has survived as a wild plant, because the pistillate spike breaks up at maturity to disperse the kernels, which, unlike maize kernels, are protected in heavy cellulose, lignin structures, called fruitcases.

Fruit cases are composed of hard segment of the rachis of the spike, and lignified outer glumes (Beadle, 1977).

Katiyar and Sachan (1992) found that the genetic distance (GD) was the least (0.309) between maize and teosient on Isozyme diversity in Zea maize and related genera.The early history of backcrossing was stated by Harian and Pope (1922) and Allard (1960). Backcross breeding is used as a conservative approach, and the goal is to improve the existing cultivars.

Srikumar and Bai (1995) evaluated nine fodder maize types and found high estimates of genotypic coefficient of variation, heritability and genetic advance, for plant height. Kumar (2000) put emphasis on maize plant height with greater ear weight, number of rows per ear and number of seeds/ear for better grain yield. A quantitative trait expresses itself in close association with many other traits-Alteration in the expression of one trait is usually associated with a change in the expression of other traits. Therefore, a plant breeder has to study the degree of characters association.

This field study was aimed to evaluate eight genotypes of teosinte obtained from the Forage Crops Research Department, FCRI, ARC, in addition to

${ }^{1}$ Forage Crops Research Department, Field Crops Research Institute, Agriculture Research Center (ARC). Giza, Egypt.

${ }^{2}$ Department of Agronomy, Faculty of Agriculture, Menoufia Univ. Egypt. Received May 24, 2018, Accepted June 27, 2018 
investigate the polyacrylamide gel electrophoresis (SDS- PAGE).

To define the best promising high yielding genotypes under this study, SDS - PAGE method was based on that of Laemmli (1970). For the determination of the protomer molecular weights, a mixture of the following marker proteins. The electrophoretic data were, statistically, analyzed by cluster and principal coordinate analysis of the matrix of similarity coefficients (Cs) to draw a relationship between the genotypes of teosinete (Sammour, 1994).

\section{MATERIALS AND METHODS}

Eight genotypes were obtained from the Forage Crops Research Department, FCRI, ARC, Giza, Egypt. The genotypes are indicated in Table (I) A field experiment was carried out at Gemmiza Experimental Research Station, El-Gharbia Governorate, ARC Egypt in 2014 and 2015 summer seasons Seeds were sown at $20 \mathrm{~kg} / \mathrm{fed}$ on May $10^{\text {th }} 2014$, and the May $18^{\text {th }} 2015$. A randomized complete block design in three replicates, was used. The experimental plot area was $12 \mathrm{~m}^{2}$. All other cultural practices were done on time. Three cuts were obtained under such conditions during the growing season Cuts were taken when plant height reached 90 to $120 \mathrm{~cm}$ according to USDA Plant Fact Sheet of Mexian Teosinte. Cuts were done about sixty days after planting for the $1^{\text {st }}$ cut, the $2^{\text {nd }}$ cut was taken after 32 days from the $1^{\text {st }}$ one, and the last cut was taken after thirty days from the $2^{\text {nd }}$ cut in both seasons. At cutting time, five plants from, each plot, were randomly taken to estimate plant height $(\mathrm{cm})$, number of leaves on the main stem, main stem diameter $(\mathrm{mm})$, measuring both the length and the maximum width of the third uppermost leaf blade on the main stem, to calculate leaf area (multiplied by $0.76 \mathrm{~cm}^{2}$ ), fresh fodder (fy) and dry (Dy) yields were estimated and then transformed to ton/fed., fresh leaves / stem (\%) and dry leaves / stem (\%). The broad - sense heritability was calculated, according to Eckebil et al. (1977) and Hamdi et al. (2003), Data were subjected to ANOVA statical analysis, using SAS and SPSS software to deduce the least significant differences (LSD) among genotypes at $(5 \%)$ level.

Analysis of variance of treatments difference was performed according to Steel and Torrie (1980). Statistical analysis was done by SAS software package (Version 9.1.3, 2007).

\section{SDS - PAGE electrophoresis :}

Total protein content was determined in grounded fine powder seeds of each sample by the method, described by Bradford (1976), using bovine serum albumin (96\%, Sigma Chemical Co, St. Louis, MO, USA), as a standard. Then, the total souble proteins was extracted with an extraction buffer. Fifty ul of the extract were mixed with $50 \mathrm{ml}$ of SDS-sample buffer (0.15 M TRIS-HC1, pH 6.8, (3\%) w/v SDS, (5\%) v/v $\beta$-mercaptoethanol, (7\%) v/v glycerol and $0.03 \%$ Bromphenol Blue) and boiled for $7 \mathrm{~min}$ in a boiling water bath. $14 \mathrm{ml}$ of the sample was loaded onto each well. Electrophoresis (SDS-PAGE) was carried out according to the procedures of Laemmli (1970) in 1.5 mm thick gels with $14 \%$ (w/v) separating gel and (4\%) (w/v) stacking gel in a vertical electrophoreses unit (Cleaver Scientific, England). SDS-PAGE was carried out at 75 volts for three hours. After electrophoresis, the gels were overnight stained using $0.1 \%$ (w/v) Coomassie Brilliant Blue R-250. Then, distained using a $(10 \%)(\mathrm{v} / \mathrm{v})$ acetic acid solution until a clear background was achieved. A Page ruler pertained protein ladder (Thermo-Fisher Scientific) was used as protein molecular weight marker. Gel documentation system (GelDoc-It ${ }^{\mathrm{e}}$ Imaging System, UVP, England), was applied for data scoring and documentation. Total lab analysis software (Total Lab TL120, v2008) was employed for constructing binary matrix for SDS PAGE data, according to presence or absence of a band of each sample, which remarked as one or zero.

\section{Protein electrophoresis studies:}

SDS polyacrylamide gel electrophoresis (SDSPAGE) $(12 \% \mathrm{~T})$ was performed to evaluate genetic variation among the eight teosinte genotypes, according to the methods of Lammli (1970).

\section{Protein extraction and purification methods: Protein precipitation :}

The proteins ware precipitately from the ethanol/phenol supernatant with $1.5 \mathrm{ml}$ isopropanol. The samples were stored at room temperature for ten minutes and was sediment the protein precipitate at $12,000 \times \mathrm{g}$ for ten minutes at $4{ }^{\circ} \mathrm{C}$. 2. Protein Wash Remove supernatant and wash the protein pellet 3 times with a $2 \mathrm{ml}$ solution of $0.3 \mathrm{M}$ guanidinium hydrochloride in $(95 \%)$ ethanol. The samples were kebt in washing solution for twenty minutes at room temperature before centrifuging at $7,500 \mathrm{x} \mathrm{g}$ for 5 minutes at $4{ }^{\circ} \mathrm{C}$. Next vortex the protein pellet once with $2 \mathrm{ml}$ of $100 \%$ ethanol, stored for twenty minutes at room temperature and centrifuged at 7,500 x $\mathrm{g}$ for five minutes at $4{ }^{\circ} \mathrm{C}$.

\section{Protein solubilization :}

Remove any ethanol and dry the protein pellet briefly for 5-10 minutes under vacuum and dissolve it in ( $1 \%$ ) SDS by pipetting it up and down. Incubation of the samples at higher temperatures $\left(50-100{ }^{\circ} \mathrm{C}\right)$ might be necessary to yield complete solubilization. Unsoluble material could be removed by centrifugation at 10,000 x 
$\mathrm{g}$ for ten minutes at $4{ }^{\circ} \mathrm{C}$. The protein supernatant should be transferred to a fresh tube. It could either be used immediately or kept frozen at $-20{ }^{\circ} \mathrm{C}$ for future use.

\section{Protein fraction quantification:}

The protein fraction concentration was determined, according to Bradford (1976) method, based on the interaction between protein and Coomassie Brillant Bleu G250 (CBBG-250) in acid conditions. An amount of $50 \mu \mathrm{l}$ of distilled water and $200 \mu$ l Coomassie Bleu Reagent were added to $50 \mu$ lof protein extract. After color stabilization for $5 \mathrm{~min}$, the absorbance at $595 \mathrm{~nm}$ was recorded. Protein sample concentrations were determined, in reference to a range of standards based on Bovin Serum Albumin (BSA). Standard's concentration varied from zero to $150 \mu \mathrm{g}$ and prepared in the same operating conditions, as samples.

Stocks solutions used for electrophoresis were as follows:

1- Acrylamide bis - acrylamide solution (30:0.8) was prepared by dissolving $30 \mathrm{~g}$ of acrylamide and 0.8 bis- acrylamide in a total volume of $100 \mathrm{ml}$ distilled water. The solution was filtered through Whatman filter paper No 1 and stored at $4 \mathrm{C}$ in a dark bottle.

2- TEMED was used as undiluted solution and stored at $4 \mathrm{C}$ in a dark bottled.

3- Ammonium per sulphate (1.5 \% w/v) was prepared by dissolving $0.15 \mathrm{~g}$ in $10 \mathrm{ml}$ water. This solution was unsuitable and was freshly prepared just before use.

4- SDS (10 \%, w/v) was prepared by dissolving $10 \mathrm{~g}$ of SDS in $100 \mathrm{ml}$ distilled water.

5- 2- mercaptoethanol was used as undiluted solution.

6- Resolving gel buffer (3.0 M Tris- Hcl, pH 8.8 ) was prepared by resolving $36.39 \mathrm{~g}$ of Tris in 48.0 $\mathrm{ml}$ of $1 \mathrm{M} \mathrm{Hcl}$ and completed to $100 \mathrm{ml}$ with distilled water. The solution was filtered through Whatman filter paper No. 1 and stored at $4^{\circ} \mathrm{C}$ until used.

7- Staking gel buffer (0.5 M Tris-Hcl pH6.8) was prepared by dissolving $6.0 \mathrm{~g}$ Tris in $40 \mathrm{ml}$ distilled water. The $\mathrm{pH}$ was adjusted to 6.8 , using $1 \mathrm{M}$ $\mathrm{Hcl}$ and completed to $100 \mathrm{ml}$ with distilled water. The solution was filtered through Whatman filter paper No.1 and stored at $4^{\circ} \mathrm{C}$ until used.

8- Resolving buffer (10 X, pH 8.6) was prepared by dissolving $30.3 \quad \mathrm{~g} \quad \operatorname{Tris}(0.25 \mathrm{M}) ; 144.0 \mathrm{~g}$ glycine $(1.92 \mathrm{M})$ and $10.0 \mathrm{~g} \operatorname{SDS}(1 \%)$ in one litter of distilled water .The solution was stored at $4^{\circ} \mathrm{C}$ until used.

\section{Preparation of slab gel:}

(13\%) slab gel was applied,s according to Bamdad et al. (2009), prepared by mixing acrylamide- bisacrylamide, $(10 \mathrm{ml})$, resolving gel buffer stock, (3.7 ml), (10\%) SDS, $(0.3 \mathrm{ml})$, freshly prepared, (1.5\%) ammonium per sulphate, $(1.5 \mathrm{ml})$, distilled water, (14.45ml) and TEMED (0.015). (4\%) stacking gel was prepared, using acrylamidebisacrylamide $(2.5 \mathrm{ml})$, stacking gel buffer stock, $(5.0$ $\mathrm{ml})$; SDS $(10 \%)(0.2 \mathrm{ml})$; freshly prepared $(1.5 \%)$ ammonium per sulphate, $(1.0 \mathrm{ml})$, distilled water $(11.3 \mathrm{ml})$ and TEMED $(0.015 \mathrm{ml})$.

\section{Loading of samples and electrophoresis:}

For each sample, after gel polymerization, $30 \mu \mathrm{g}$ proteins were loaded and electrophoresis was performed at 75 volt, through stacking gel, followed by $125 \mathrm{v}$, during approximately $2 \mathrm{~h}$.

\section{Protein staining:}

Gel was stained by $(0.1 \%)$ comassie blue R- 250 for $2 \mathrm{~h}$. Then, distained with a solution $(1: 3: 6)$ of glacial acetic acid, methanol, and water, respectively.

\section{Data analysis:}

Gel documentation system (Geldoc-it, UVP, England) was applied for data analysis, using Totallab analysis software, ww.totallab.com, (Ver.1.0.1).

Table 1. The eight genotypes of teosinte

\begin{tabular}{ccc}
\hline $\begin{array}{c}\text { Number of } \\
\text { genotypes }\end{array}$ & Genotypes & Origin \\
\hline 1 & Teosinte Genotype & Egypt \\
2 & Teosinte Genotype & Egypt \\
3 & Teosinte Genotype & Egypt \\
4 & Teosinte Genotype & Egypt \\
5 & Teosinte Genotype & Egypt \\
6 & Teosinte Genotype & Egypt \\
7 & Teosinte Genotype & Egypt \\
8 & Teosinte Genotype & Egypt \\
\hline
\end{tabular}

\section{RERSULTS AND DISCUSSION}

\section{Plant height :}

Plant height (ph) at cutting time is presented in Tables (2 and 11). As noticed in the previous characters, the second cut had the tallest plants. At the $2^{\text {nd }}$ cut, the mean ph over all genotypes, was $121.6 \mathrm{~cm}$, in 2014 and $122.3 \mathrm{~cm}$, in 2015 . Concerning genotypes differences in $\mathrm{ph}$, the tallest plants were recorded by genotype 3 , followed by genotype 4 in both seasons, where, the shortest genotypes were genotype 8, genotype 6 and genotype 5. These results are in agreement with those of Hong et al. (1987), Which supported the importance of plant height character, which affected different 
morphological characters of plant, Amos et al. (2009) stated that, as moisture content increased, the plant height.

\section{Stem diameter :}

Main stem diamater ( $\mathrm{SD}, \mathrm{mm}$ ), as one of the phenotypic characters to evaluate different genotypes of teosinte, was recorded in Tables (3 and 12). Data showed that genotype 3 and genotype 4 had the highest $\mathrm{SD}$ among the other genotypes, whereas, the lowest SD value was recorded for genotype 5 in both seasons. Similar results have been reported by Muhammad et al. (2006) and Hong et al. (1987), who reported that stem diameter of both maize and cowpea or soybean plants were, significantly, inflounced by seed combination.

\section{Number of leaves (NL) :}

The high yielding genotypes had more leaves (on the main stem) than the low yielding ones (Tables 4 and 13). The mean number of leaves (NL) of the second cut (in both seasons) was the best with 13.2 and 13.2 leaves in the two seasons, respectively, compared to the $1^{\text {st }}$ and $3^{\text {rd }}$ cuts. NL was slightly higher in the $1^{\text {st }}$ cut over the $3^{\text {rd }}$ one. The best genotypes, in NL, were genotype 3 and genotype 4 in the same order. Genotype 4 had the highest NL (13.1 and 14.8 leaves) in the two seasons of study. The lowest was G.8 (8.7 and 8.5 leaves) in the two seasons, respectively. These results are in agreement with those of Patrick et al. (2008).

\section{Leaf area $\left(\mathrm{LA}, \mathrm{cm}^{2}\right)$ :}

Leaf area $\left(\mathrm{LA}, \mathrm{cm}^{2}\right)$ of the fully expanded $3^{\text {rd }}$ leaf (from top on the main stem) was shown in Tables (5 and 14). The mean LA, significantly increased from the $1^{\text {st }}$ cut to the $2^{\text {nd }}$ cut, and then, decreased at the $3^{\text {rd }}$ cut in both seasons. Data revealed that genotype 3 and genotype 4 were the highest values for LA at the three cuts in both seasons. Similar results have been reported by Kim and Seo (1988) and Nawaz et al. (2004), Who stated that leaf area might be attributed to variation in genetic makeup and adaptability of the plants to different environmental conditions.

\section{Dry matter (DM):}

Dry matter (DM) of the tested genotypes, for three cuts, was presented in Tables (6 and 15). The mean DM of the second cut was significantly higher (19.6 and 20.2 in the $1^{\text {st }}$ and $2^{\text {nd }}$ seasons, respectively). compared to the other cuts. Genotype 3 and genotype 4 were the best producing $(21.1,20.9)$ and $(21.7,21.1)$ in 2014 and 2015, respectively. However, the lowest ones were 1, 2, 5, 6, 7 and 8 genotypes in dry matter recorded in the two seasons, Similar results have been reported by Frandsen (1986) and Kinght et al. (1996).

\section{Fresh yield (Fy) :}

Fresh yield (Fy) of the eight genotypes was shown in Tables (7 and 16). In general, Fy was slightly higher in the first season, in comparison with the second one, It was also noticed the FY, at the second cut, was significantly, higher than that of the first or third cuts in both seasons the total FY ranged from (38.4) t/fed, for genotype G3 to (47.9) t/fed for G4, in 2014 season, whereas it ranged from (36.3) t/fed for G3, to (37.3) T/Fed for G4 in 2015 season. G3 had the highest total fresh yield in both seasons, followed by G4, compared to the other tested genotypes. Similar results have been reported by Patrick et al. (2008) and Knight et al. (1996).

\section{Fresh leaves/stem(\%) :}

Fresh leaves (FL/stem) of the tested genotypes for the three cuts, were presented in Tables ( 9 and 18) the mean (FL/stem) of the first and second cuts were significantly higher (204.4 and 75.5), in 2014 season, (168.2 and 71.7) in 2015 season, respectively compared to the third cut. Concerning the mean of the three cuts, genotype 3 and G4 were the best genotypes, producing (149.8 and 155.0) in 2014 season, (107.5 and 112.7) in 2015 season. The results are in agreement with those reported by Patrick et al. (2008).

\section{Dry yield (DY) :}

Dry yield (DY) of the tested genotypes for the three cuts, was presented in Tables (8 and 17). The mean DY, of the second cut, was significantly, higher (3.5 and 3.3 $\mathrm{t} / \mathrm{fed}$, in the $1^{\text {st }}$ and $2^{\text {nd }}$ seasons, respectively), compared to the other cuts. Concerning the total dry yield of the three cuts, genotype 3 was the best producing ( 8.2 and $7.8 \mathrm{t} / \mathrm{fed}$ ) in 2014 and 2015, respectively. G3 and G4 were the best genotypes in this concern. The results are in agreement with those reported by Frandsen (1986), Knight et al. (1996) and Patricket et al. (2008).

\section{Dry leaves / stem (\%) :}

Dry leaves / stem of the tested genotypes for the three cuts, were presented in Tables (10 and 19). The mean (Dry L / S) of the first and second cuts were, significantly higher (286.3 and 117.4) in 2014 season, and (273.4 and 136.4) in 2015 season, respectively, compared to the third cut. Concerning the mean of the three cuts, genotype 3 and genotype 4 were the best genotypes producing (230.9 and 218.3) in 2014 season, (223.8 and 247.3) in 2015 season. Similar results have been reported by Patrick et al. (2008).

\section{Correlation coefficients :}

Correlation coefficients, among the studied traits of teosinte genotypes were calculated and presented in Tables (22 and 23). Data revealed highly positive significant correlations among plant height, stem 
dimeter, number of leaves / plant, dry matter, fresh yield and dry yield.

Less positive correlation coefficient values, for the fresh leaves / stem\% and dry leaves / stem (\%) with previous characters, were found in 2014 and 2015 seasons. Similar results have been reported by (Frandsen, 1986).

Table 2. Plant height (cm) at cutting time for eight teosinte genotypes in 2014 season

\begin{tabular}{ccccc}
\hline Genotypes & \multicolumn{3}{c}{$\mathbf{2 0 1 4}$ season } \\
\cline { 2 - 5 } & $\mathbf{1}^{\text {st }} \mathbf{C}$ & $\mathbf{2}^{\text {nd }} \mathbf{C}$ & $\mathbf{3}^{\text {rd }} \mathbf{C}$ & Mean \\
\hline 1 & 105.3 & 120.7 & 94.7 & 106.9 \\
2 & 106.0 & 123.7 & 100.7 & 110.1 \\
3 & 122.0 & 135.0 & 116.7 & 124.3 \\
4 & 114.3 & 137.7 & 116.7 & 122.9 \\
5 & 102.0 & 114.7 & 94.0 & 103.6 \\
6 & 103.7 & 105.3 & 87.0 & 98.7 \\
7 & 104.3 & 117.0 & 91.0 & 99.1 \\
8 & 96.0 & 118.7 & 84.7 & - \\
Mean & 106.7 & 121.6 & 98.2 & \\
L.S.D. (5\%) & Cuts, C $=2.17$ & $\mathrm{G}=2.11$ & $\mathrm{C} * \mathrm{G}=6.6$ \\
CV $(\%)$ & \multicolumn{2}{c}{2.04} \\
\hline
\end{tabular}

Table 3. Stem diameter $(\mathrm{mm})$ at cutting time for eight teosinte genotypes in 2014 season

\begin{tabular}{ccccc}
\hline Genotypes & \multicolumn{3}{c}{$\mathbf{2 0 1 4}$ season } \\
\cline { 2 - 5 } & $\mathbf{1}^{\text {st }} \mathbf{C}$ & $\mathbf{2}^{\text {nd }} \mathbf{C}$ & $\mathbf{3}^{\text {rd }} \mathbf{C}$ & Mean \\
\hline 1 & 8.7 & 14.7 & 7.7 & 10.3 \\
2 & 7.7 & 14.0 & 8.3 & 10.0 \\
3 & 7.7 & 16.0 & 11.3 & 11.7 \\
4 & 9.3 & 16.3 & 12.7 & 12.8 \\
5 & 8.3 & 13.0 & 7.7 & 9.7 \\
6 & 10.7 & 15.3 & 11.0 & 12.3 \\
7 & 9.3 & 13.0 & 8.3 & 9.9 \\
8 & 8.7 & 12.3 & 8.7 & - \\
Mean & 8.8 & 14.3 & 9.4 & \\
L.S.D. $(5 \%)$ & Cuts, C $=0.32$ & $\mathrm{G}=0.58$ & $\mathrm{C} * \mathrm{G}=1.02$ \\
CV $(\%)$ & \multicolumn{2}{c}{5.67} \\
\hline
\end{tabular}

Table 4 . Number of leaves / plant at cutting time for eight teosinte genotypes in 2014 season

\begin{tabular}{ccccc}
\hline Genotypes & \multicolumn{5}{c}{$\mathbf{2 0 1 4}$ season } \\
\cline { 2 - 5 } & $\mathbf{1}^{\text {st }} \mathbf{C}$ & $\mathbf{2}^{\text {nd }} \mathbf{C}$ & $\mathbf{3}^{\text {rd }} \mathbf{C}$ & Mean \\
\hline 1 & 9.0 & 10.7 & 7.3 & 9.0 \\
2 & 7.3 & 12.3 & 8.3 & 9.3 \\
3 & 9.3 & 17.3 & 10.3 & 12.3 \\
4 & 10.0 & 18.0 & 11.3 & 13.1 \\
5 & 8.3 & 13.3 & 7.3 & 9.7 \\
6 & 8.3 & 12.0 & 9.0 & 9.8 \\
7 & 8.7 & 11.0 & 8.3 & 8.7 \\
8 & 7.7 & 11.3 & 7.0 & - \\
Mean & 8.5 & 13.2 & 8.6 & \\
L.S.D. $(5 \%)$ & Cuts, C $=0.70$ & $\mathrm{G}=0.71$ & $\mathrm{C} * \mathrm{G}=1.23$ \\
CV $(\%)$ & \multicolumn{5}{c}{7.40} \\
\hline
\end{tabular}


Table 5. Leaves area / plant $\left(\mathrm{cm}^{2}\right)$ at cutting time for eight teosinte genotypes in 2014 season

\begin{tabular}{ccccc}
\hline Genotypes & \multicolumn{4}{c}{$\mathbf{2 0 1 4}$ season } \\
\cline { 2 - 5 } & $\mathbf{1}^{\text {st }} \mathbf{C}$ & $\mathbf{2}^{\text {nd }} \mathbf{C}$ & $\mathbf{3}^{\text {rd }} \mathbf{C}$ & Mean \\
\hline 1 & 2917.5 & 3670.0 & 1304.9 & 2630.8 \\
2 & 1855.4 & 3735.2 & 2530.9 & 2707.2 \\
3 & 3520.1 & 7779.4 & 4055.5 & 5118.4 \\
4 & 3900.3 & 8659.7 & 4093.9 & 5551.3 \\
5 & 2385.1 & 4127.4 & 803.2 & 2438.6 \\
6 & 3080.7 & 3037.4 & 1549.5 & 2555.9 \\
7 & 2818.6 & 2611.2 & 1285.9 & 2238.6 \\
8 & 2255.6 & 3527.7 & 1150.5 & 2311.3 \\
Mean & 2841.6 & 4643.5 & 2096.7 & - \\
L.S.D. (5\%) & Cuts, C $=259.11$ & $\mathrm{G}=286.98$ & \\
CV(\%) & \multicolumn{3}{c}{ C $*$ G $=157.34$} \\
\hline
\end{tabular}

Table 6. Dry matter at cutting time for eight teosinte genotypes in 2014 season

\begin{tabular}{ccccc}
\hline Genotypes & \multicolumn{4}{c}{$\mathbf{2 0 1 4}$ season } \\
\cline { 2 - 5 } & $\mathbf{1}^{\text {st }} \mathbf{C}$ & $\mathbf{2}^{\text {nd }} \mathbf{C}$ & $\mathbf{3}^{\text {rd }} \mathbf{C}$ & Mean \\
\hline 1 & 18.0 & 18.4 & 18.9 & 18.4 \\
2 & 17.2 & 21.9 & 21.6 & 20.2 \\
3 & 18.9 & 22.3 & 22.2 & 21.1 \\
4 & 18.6 & 21.4 & 22.7 & 20.9 \\
5 & 18.8 & 18.1 & 18.4 & 18.5 \\
6 & 18.6 & 18.8 & 19.2 & 18.9 \\
7 & 18.6 & 18.6 & 18.3 & 17.9 \\
8 & 18.1 & 17.7 & 18.1 & - \\
Mean & 18.3 & 19.6 & 19.9 & \\
L.S.D. $(5 \%)$ & Cuts, C $=0.07$ & $\mathrm{G}=0.13$ & $\mathrm{C} * \mathrm{G}=0.16$ \\
CV $(\%)$ & \multicolumn{3}{c}{0.72} \\
\hline
\end{tabular}

Table 7. Fresh yield (ton/fed) at cutting time fore eight teosinte genotypes in 2014 season

\begin{tabular}{|c|c|c|c|c|}
\hline \multirow[t]{2}{*}{ Genotypes } & \multicolumn{4}{|c|}{2014 season } \\
\hline & $1^{\text {st }} \mathrm{C}$ & $2^{\text {nd }} \mathrm{C}$ & $3^{\text {rd }} \mathrm{C}$ & Total \\
\hline 1 & 6.7 & 12.7 & 2.8 & 22.2 \\
\hline 2 & 6.4 & 21.8 & 4.8 & 33.0 \\
\hline 3 & 9.2 & 23.4 & 5.8 & 38.4 \\
\hline 4 & 9.3 & 22.8 & 5.8 & 37.9 \\
\hline 5 & 6.3 & 16.3 & 3.7 & 26.3 \\
\hline 6 & 9.2 & 18.7 & 4.7 & 32.6 \\
\hline 7 & 7.7 & 15.5 & 3.8 & 27.0 \\
\hline 8 & 6.8 & 13.3 & 3.5 & 23.6 \\
\hline Mean & 7.7 & 18.1 & 4.3 & - \\
\hline L.S.D. $(5 \%)$ & \multirow{2}{*}{\multicolumn{4}{|c|}{$\begin{array}{c}\mathrm{C} * \mathrm{G}=0.16 \\
1.05\end{array}$}} \\
\hline $\mathrm{CV}(\%)$ & & & & \\
\hline
\end{tabular}

\section{Broad sense heritability :}

Data in Tables (20 and 21) showed the phenotypic coefficient variance $(\operatorname{PCV}(\%))$, genetic $\left(\delta^{2} g\right)$, environment $\left(\delta^{2} e\right)$, phenotypic variations $\left(\delta^{2} \mathrm{p}\right)$, broad sense heritability $\left(\mathrm{h}^{2} \mathrm{~b} \%\right)$ and mean estimates for plant height $(\mathrm{pH})$, stem diameter (SD), number of leaves / plant (NL), leaves area (LA), dry matter (DM), fresh yield (fy), dry yield (Dy), fresh leaves / stem (FL/s) and dry leaves / stem (DL/s).

The heritability percentages were high in fresh yield, dry matter, leave area, plant height, stem diameter (99.9, 
99.8, 99.5, 99.5 and 99.1, respectively) while fresh leaves / stem (FL/S) had the lowest value of $h^{2} b$ (86.2\%).

Heritability ranged from $(86.2$ to $99.9 \%)$ and was considered important in selection of different teosinte genotypes. The high heritability values indicated that the predominance of additive gene action in the expression of the traits, which could be improved through single cycle of slection. These results are in agreement with those of Manggoel et al. (2012) and Rashwan (2010).

Tables (20 and 21) show the genotypic $\left(\delta^{2} g\right.$ ) and phenotypic variation $(\delta \geq P)$. Genotypic coefficient of variation $(\mathrm{Gcv})$, phenotypic coefficient of variance $(\mathrm{Pcv})$, broad sense heritability $\left(\mathrm{h}^{2}\right)$. Generally, PCV had higher values than that of Gcv, which indicated some environmental implication a long side genotypic reasons of variation, observed among genotypes used in this study.

Phenotypic variance was higher than the genetic variance for all morphological traits. This observed variation might be due to environmental factors rather

Table 8. Dry yield (ton/fed) at cutting time for eight teosinte genotypes in 2014 season

\begin{tabular}{ccccc}
\hline Genotypes & \multicolumn{3}{c}{$\mathbf{2 0 1 4}$ season } \\
\cline { 2 - 5 } & $\mathbf{1}^{\text {st }} \mathbf{C}$ & $\mathbf{2}^{\text {nd }} \mathbf{C}$ & $\mathbf{3}^{\text {rd }} \mathbf{C}$ & Total \\
\hline 1 & 1.2 & 2.3 & 0.53 & 4.03 \\
2 & 1.1 & 3.7 & 1.1 & 6.9 \\
3 & 1.7 & 5.2 & 1.3 & 8.2 \\
4 & 1.7 & 4.8 & 1.3 & 7.8 \\
5 & 1.2 & 2.9 & 0.69 & 4.7 \\
6 & 1.7 & 3.5 & 0.91 & 4.1 \\
7 & 1.4 & 2.8 & 0.71 & 4.2 \\
8 & 1.2 & 2.4 & 0.64 & - \\
Mean & 1.4 & 3.5 & 0.89 & \\
L.S.D. $(5 \%)$ & Cuts, C 0.02 & $\mathrm{G}=0.02$ & $\mathrm{C} * \mathrm{G}=0.16$ \\
CV $(\%)$ & \multicolumn{2}{c}{1.2} \\
\end{tabular}

than genetic ones. Similar results have been reported by Nwosu et al. (2013). The heritability in broad sense was significantly higher for all the traits under investigation, it ranged from (86.2 to 99.9\%). in 2014 season. Also it ranged from (95.6 to $99.9 \%$ ) in 2015 season and was considered important in selection of different teosinte genotypes from a population (Manggoel et al. 2012), (Sharma and Singhania, 1992) and (Rashwan, 2010). The high $\mathrm{h}^{2}$ values indicate that the predominace of additive gene action in the expression of the traits, which could be improved through a signal cycle of selection.

SDS - PAGE technique gave a huge help for evaluation teosinte genotypes, Generally, highly genetic variation was detected for the eight genotypes (Figures 1, 2 and 3).

Data in Tables (25 and 28), showed the total soluble protein, studying via SDS - PAGE technique, all teosinte genotypes reflected variable distinguishable protein fragments, on one hand, genotype I of teosinte was superior in protein band number with 21 fragments.

Table 9. Fresh leaves / stem $(\%)$ at cutting time for eight teosinte genotypes in 2014 season

\begin{tabular}{|c|c|c|c|c|}
\hline \multirow[t]{2}{*}{ Genotypes } & \multicolumn{4}{|c|}{2014 season } \\
\hline & $1^{\text {st }} \mathrm{C}$ & $2^{\text {nd }} C$ & $3^{\text {rd }} \mathrm{C}$ & Mean \\
\hline 1 & 168.9 & 77.1 & 63.1 & 103.0 \\
\hline 2 & 213.9 & 62.1 & 62.0 & 112.7 \\
\hline 3 & 293.1 & 82.1 & 74.2 & 149.8 \\
\hline 4 & 307.4 & 86.4 & 71.2 & 155.0 \\
\hline 5 & 179.1 & 66.3 & 46.1 & 97.1 \\
\hline 6 & 214.6 & 68.7 & 58.5 & 113.9 \\
\hline 7 & 126.1 & 86.3 & 65.8 & 92.7 \\
\hline 8 & 132.4 & 75.5 & 53.6 & 87.2 \\
\hline Mean & 204.4 & 75.5 & 61.8 & - \\
\hline \multirow{2}{*}{\multicolumn{5}{|c|}{ Cuts, $C=19.0$}} \\
\hline & & & & \\
\hline $\mathrm{CV}(\%)$ & \multicolumn{4}{|c|}{24.9} \\
\hline
\end{tabular}


Table 10. Dry leaves / stem (\%) at cutting time for eight teosinte genotypes in 2014 season

\begin{tabular}{ccccc}
\hline Genotypes & \multicolumn{3}{c}{$\mathbf{2 0 1 4}$ season } \\
\cline { 2 - 5 } & $\mathbf{1}^{\text {st }} \mathbf{C}$ & $\mathbf{2}^{\text {nd }} \mathbf{C}$ & $\mathbf{3}^{\text {rd }} \mathbf{C}$ & Mean \\
\hline 1 & 235.2 & 126.5 & 142.8 & 168.2 \\
2 & 254.8 & 85.8 & 113.2 & 151.2 \\
3 & 402.4 & 153.6 & 136.9 & 230.9 \\
4 & 395.1 & 151.6 & 108.2 & 218.3 \\
5 & 250.7 & 105.8 & 98.1 & 151.5 \\
6 & 332.8 & 98.3 & 93.6 & 174.9 \\
7 & 210.7 & 106.7 & 113.4 & 143.6 \\
8 & 208.8 & 111.4 & 104.9 & - \\
Mean & 286.3 & 117.4 & 113.8 & \\
L.S.D. $(5 \%)$ & Cuts, C $=0.80$ & $\mathrm{G}=2.29$ & $\mathrm{C} * \mathrm{G}=3.97$ \\
CV $(\%)$ & \multicolumn{3}{c}{1.39} \\
\hline
\end{tabular}

Table 11. Plant height $(\mathrm{cm})$ at cutting time for eight teosinte genotypes in 2015 season

\begin{tabular}{|c|c|c|c|c|}
\hline \multirow[t]{2}{*}{ Genotypes } & \multicolumn{4}{|c|}{2015 season } \\
\hline & $\mathbf{1}^{\text {st }} \mathrm{C}$ & $2^{\text {nd }} \mathrm{C}$ & $3^{\text {rd }} \mathrm{C}$ & Mean \\
\hline 1 & 111.0 & 117.7 & 81.3 & 103.3 \\
\hline 2 & 106.3 & 122.3 & 95.7 & 108.1 \\
\hline 3 & 116.0 & 136.3 & 112.7 & 121.7 \\
\hline 4 & 111.3 & 135.7 & 109.3 & 118.7 \\
\hline 5 & 103.0 & 121.7 & 85.7 & 103.4 \\
\hline 6 & 106.7 & 115.3 & 101.0 & 107.6 \\
\hline 7 & 101.0 & 112.0 & 98.7 & 103.8 \\
\hline 8 & 96.3 & 118.0 & 88.7 & 101.1 \\
\hline Mean & 106.4 & 122.3 & 96.6 & - \\
\hline L.S.D. $(5 \%)$ & Cuts, $\mathrm{C}=1.21$ & $\mathrm{G}=$ & & \\
\hline $\mathrm{CV}(\%)$ & & & & \\
\hline
\end{tabular}

Table 12. Stem diameter $(\mathrm{mm})$ at cutting time for eight teosinte genotypes in 2015 season

\begin{tabular}{ccccc}
\hline Genotypes & \multicolumn{5}{c}{ 2015 season } \\
\cline { 2 - 5 } & $\mathbf{1}^{\text {st }} \mathbf{C}$ & $\mathbf{2}^{\text {nd }} \mathbf{C}$ & $\mathbf{3}^{\text {rd }} \mathbf{C}$ & Mean \\
\hline 1 & 11.3 & 16.0 & 8.6 & 12.0 \\
2 & 8.6 & 18.3 & 12.0 & 13.0 \\
3 & 13.3 & 20.6 & 14.3 & 16.1 \\
4 & 13.0 & 21.3 & 15.6 & 16.6 \\
5 & 9.3 & 13.3 & 8.6 & 10.4 \\
6 & 12.3 & 15.0 & 11.3 & 12.8 \\
7 & 11.0 & 13.6 & 8.3 & 11.0 \\
8 & 11.6 & 16.0 & 8.6 & - \\
Mean & 11.3 & 16.7 & 10.9 & \\
L.S.D. $(5 \%)$ & Cuts, C $=0.97$ & $\mathrm{G}=0.62$ & $\mathrm{C} * \mathrm{G}=1.07$ \\
CV $(\%)$ & \multicolumn{2}{c}{4.99} \\
\hline
\end{tabular}


Table 13. Number of leaves / plant at cutting time for eight teosinte genotypes in 2015 season

\begin{tabular}{ccccc}
\hline Genotypes & \multicolumn{3}{c}{$\mathbf{2 0 1 5}$ season } \\
\cline { 2 - 5 } & $\mathbf{1}^{\text {st }} \mathbf{C}$ & $\mathbf{2}^{\text {nd }} \mathbf{C}$ & $\mathbf{3}^{\text {rd }} \mathbf{C}$ & Mean \\
\hline 1 & 9.3 & 12.0 & 8.0 & 9.7 \\
2 & 9.0 & 13.6 & 10.3 & 11.0 \\
3 & 10.3 & 15.3 & 11.6 & 12.4 \\
4 & 11.0 & 18.6 & 15.0 & 14.8 \\
5 & 9.6 & 11.6 & 9.0 & 10.1 \\
6 & 9.3 & 12.3 & 8.3 & 9.0 \\
7 & 8.3 & 11.6 & 7.6 & 8.5 \\
8 & 8.0 & 10.6 & 7.0 & - \\
Mean & 9.3 & 13.2 & 9.6 & \\
L.S.D. $(5 \%)$ & Cuts, C 0.56 & $\mathrm{G}=0.77$ & $\mathrm{C} * \mathrm{G}=1.34$ \\
CV $(\%)$ & \multicolumn{2}{c}{7.58} \\
\hline
\end{tabular}

Table 14. Leaves area / plant $\left(\mathrm{cm}^{2}\right)$ at cutting time for eight teosinte genotypes in 2015 season

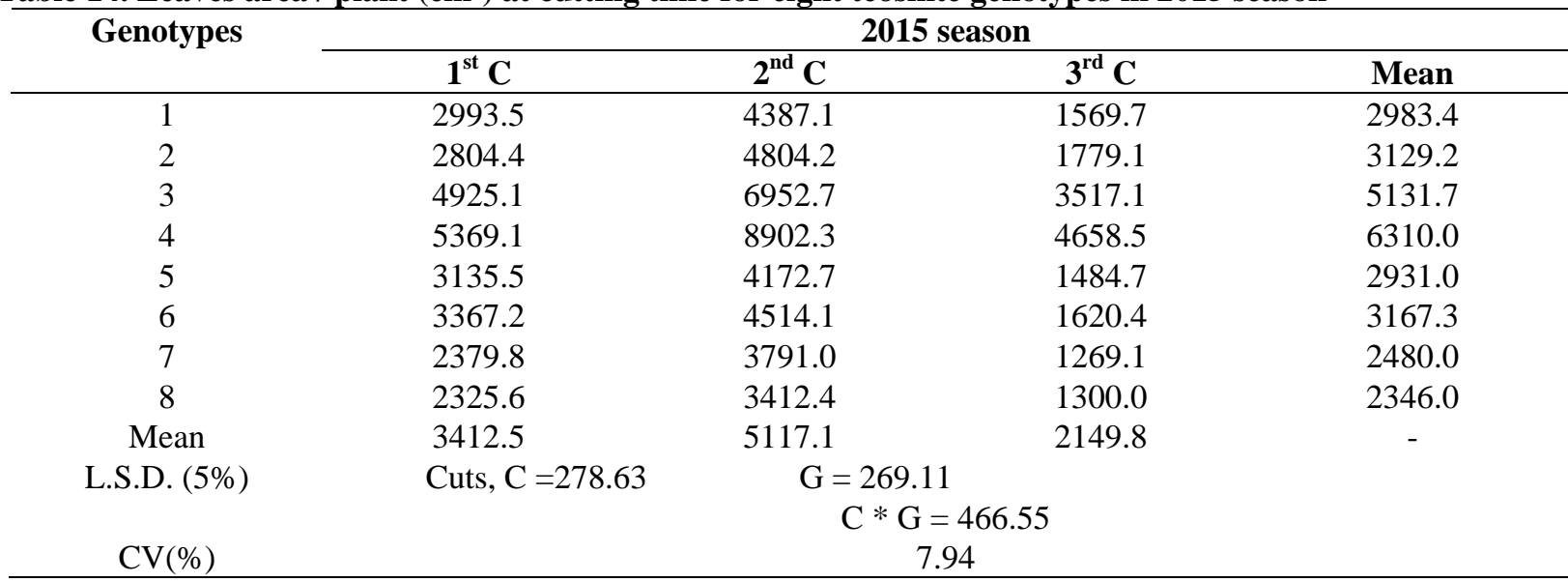

Table 15. Dry matter at cutting time for eight teosinte genotypes in 2015 season

\begin{tabular}{|c|c|c|c|c|}
\hline \multirow[t]{2}{*}{ Genotypes } & \multicolumn{4}{|c|}{2015 season } \\
\hline & $\mathbf{1}^{\text {st }} \mathrm{C}$ & $2^{\text {nd }} C$ & $3^{\text {rd }} \mathrm{C}$ & Mean \\
\hline 1 & 18.4 & 18.5 & 19.1 & 18.7 \\
\hline 2 & 17.7 & 21.8 & 22.6 & 20.7 \\
\hline 3 & 18.7 & 22.7 & 23.8 & 21.7 \\
\hline 4 & 18.7 & 21.9 & 22.6 & 21.1 \\
\hline 5 & 19.5 & 19.7 & 19.7 & 19.6 \\
\hline 6 & 18.6 & 18.8 & 20.0 & 19.1 \\
\hline 7 & 18.6 & 18.9 & 18.7 & 18.7 \\
\hline 8 & 17.9 & 19.0 & 19.1 & 18.7 \\
\hline Mean & 18.5 & 20.2 & 20.7 & - \\
\hline L.S.D. (5\%) & Cuts, $C=0.10$ & $\mathrm{G}=$ & & \\
\hline $\mathrm{CV}(\%)$ & & & & \\
\hline
\end{tabular}

On the other hand, genotype 4 of teosinte expressed the lowest protein pattern with sixteen fragments.

Results of cluster analysis are, graphically, illustrated in a dendrogram (Fig. 5). Data revelead that the studied traits showed diversity among teosinte genotypes. The data showed the lowest polymorphism level (5.5\%) between G3 and G6. On the other hand, the highest level of polymorphism was $(15.1-23.8 \%)$ between GI and G7.

The following level of polymorphism was (9.5 $11.1 \%$ ) for $\mathrm{G} 2$ and G8. Also, the data showed the lowest similarity level $(80.25 \%)$ between G1 and G7. 
On the other hand, the highest level of similarity was (94.3\%) between G3 and G5. The following level of similarity was $(89.7 \%)$ for G2 and G8.

The dendrogram showed the relationships among the eight teosinte genotypes. The genotypes were

Table 16. Fresh yield (ton/fed) at cutting time for eight teosinte genotypes in 2015 season

\begin{tabular}{ccccc}
\hline \multirow{2}{*}{ Genotypes } & \multicolumn{3}{c}{$\mathbf{2 0 1 5}$ season } \\
\cline { 2 - 5 } & $\mathbf{1}^{\text {st }} \mathbf{C}$ & $\mathbf{2}^{\text {nd }} \mathbf{C}$ & $\mathbf{3}^{\text {rd }} \mathbf{C}$ & Total \\
\hline 1 & 6.8 & 11.6 & 2.8 & 21.2 \\
2 & 6.3 & 20.8 & 4.2 & 31.3 \\
3 & 9.4 & 21.2 & 5.7 & 36.3 \\
4 & 9.3 & 22.2 & 5.8 & 37.3 \\
5 & 6.6 & 11.6 & 3.0 & 21.2 \\
6 & 9.2 & 16.7 & 4.4 & 30.3 \\
7 & 7.8 & 15.6 & 3.2 & 26.6 \\
8 & 7.4 & 14.4 & 3.6 & - \\
Mean & 7.8 & 16.7 & 4.1 & \\
L.S.D. (5\%) & Cuts, C & $\mathrm{G}=0.10$ & $\mathrm{C} * \mathrm{G}=0.16$ \\
CV(\%) & \multicolumn{2}{c}{1.11} \\
\hline
\end{tabular}

Table 17. Dry yield (ton/fed) at cutting time for eight Teosinte genotypes in 2015 season

\begin{tabular}{ccccc}
\hline Genotypes & \multicolumn{5}{c}{$\mathbf{2 0 1 5}$ season } \\
\cline { 2 - 5 } & $\mathbf{1}^{\text {st }} \mathbf{C}$ & $\mathbf{2}^{\text {nd }} \mathbf{C}$ & $\mathbf{3}^{\text {rd }} \mathbf{C}$ & Total \\
\hline 1 & 1.2 & 1.6 & 0.54 & 3.3 \\
2 & 1.1 & 4.5 & 0.96 & 6.5 \\
3 & 1.7 & 4.8 & 1.36 & 7.8 \\
4 & 1.7 & 4.8 & 1.32 & 7.8 \\
5 & 1.2 & 2.3 & 0.59 & 4.1 \\
6 & 1.7 & 3.1 & 0.88 & 5.6 \\
7 & 1.4 & 2.9 & 2.40 & 4.7 \\
8 & 1.3 & 2.7 & 0.70 & - \\
Mean & 1.4 & 3.3 & 1.1 & \\
L.S.D. $(5 \%)$ & Cuts, C 1.6 & $\mathrm{G}=2.2$ & $\mathrm{C} * \mathrm{G}=3.97$ \\
CV(\%) & \multicolumn{2}{c}{1.1} & \\
\hline
\end{tabular}

Table 18. Fresh leaves/stem (\%) at cutting time for eight teosinte genotypes in 2015 season

\begin{tabular}{|c|c|c|c|c|}
\hline \multirow[t]{2}{*}{ Genotypes } & \multicolumn{4}{|c|}{2015 season } \\
\hline & $1^{\text {st }} \mathrm{C}$ & $2^{\text {nd }} C$ & $3^{\text {rd }} \mathrm{C}$ & Mean \\
\hline 1 & 133.3 & 76.4 & 53.4 & 87.7 \\
\hline 2 & 162.4 & 57.9 & 56.4 & 92.2 \\
\hline 3 & 168.2 & 83.3 & 71.0 & 107.5 \\
\hline 4 & 196.4 & 66.3 & 75.3 & 112.7 \\
\hline 5 & 164.0 & 67.0 & 53.5 & 94.8 \\
\hline 6 & 152.7 & 60.9 & 58.3 & 90.6 \\
\hline 7 & 168.2 & 86.1 & 53.1 & 102.4 \\
\hline 8 & 201.0 & 76.4 & 62.3 & 113.2 \\
\hline Mean & 168.2 & 71.7 & 60.4 & - \\
\hline L.S.D. $(5 \%)$ & Cuts, $\mathrm{C}=2.1$ & $\mathrm{G}=2.4$ & & \\
\hline \multicolumn{5}{|c|}{$\mathrm{C} * \mathrm{G}=4.23$} \\
\hline $\mathrm{CV}(\%)$ & \multicolumn{4}{|c|}{2.5} \\
\hline
\end{tabular}

divided into three main groups and to sub-groups. The genotypes (1 and 8$)$ were in one group. While genotypes $(3,4,5,6$ and 7$)$ were in different groups and genotype (2) in another group as shown in (Fig. 5) cluster. 
Table 19. Dry leaves / stem (\%) at cutting time for eight teosinte genotypes in 2015 season

\begin{tabular}{|c|c|c|c|c|}
\hline \multirow[t]{2}{*}{ Genotypes } & \multicolumn{4}{|c|}{2015 season } \\
\hline & $\mathbf{1}^{\text {st }} \mathrm{C}$ & $2^{\text {nd }} C$ & $3^{\text {rd }} \mathrm{C}$ & Mean \\
\hline 1 & 272.1 & 152.5 & 122.3 & 182.3 \\
\hline 2 & 244.2 & 111.5 & 125.3 & 160.3 \\
\hline 3 & 354.5 & 176.3 & 140.8 & 223.8 \\
\hline 4 & 395.1 & 181.8 & 164.9 & 247.3 \\
\hline 5 & 223.3 & 119.1 & 97.0 & 146.4 \\
\hline 6 & 274.6 & 109.9 & 98.8 & 161.1 \\
\hline 7 & 200.2 & 123.4 & 113.7 & 145.7 \\
\hline 8 & 223.2 & 116.7 & 124.2 & 154.7 \\
\hline Mean & 273.4 & 136.4 & 123.3 & - \\
\hline L.S.D. (5\%) & Cuts, $C=20.6$ & & & \\
\hline $\mathrm{CV}(\%)$ & \multicolumn{4}{|c|}{$\begin{array}{c}\mathrm{C} * \mathrm{G}=38.98 \\
13.2\end{array}$} \\
\hline
\end{tabular}

Table 20. Genetics ( $\delta^{2} g$ ), environment $\left(\delta^{2} e\right)$ and phenotypic $\left(\delta^{2} p\right)$ variations, phenotypic coefficient variance $(\mathrm{PCV}(\%))$, broad sense heritability $\left(\mathrm{h}^{2} \mathrm{~b} \%\right)$ and mean estimates for PH, SD, (NL), LA, DM, FY, DY, FL/S and DL/S during 2014 season

\begin{tabular}{cccccccc}
\hline Traits & $\delta^{2} g$ & $\delta^{2} e$ & $\delta^{2} p$ & GCV & PCV \% & $\mathbf{h}^{2} \mathbf{b} \%$ & mean \\
\hline PH & 867.7 & 4.94 & 372.65 & 0.27 & 2.04 & 99.43 & 108.79 \\
SD & 12.86 & 0.37 & 13.23 & 0.33 & 5.66 & 97.2 & 10.86 \\
NL/Plant & 23.56 & 0.56 & 24.12 & 0.47 & 7.40 & 97.7 & 10.15 \\
DM & 13.82 & 0.01 & 13.84 & 0.19 & 0.72 & 99.8 & 19.32 \\
FY & 38.9 & 0.0112 & 38.99 & 0.61 & 1.05 & 99.9 & 10.06 \\
DY & 2.67 & 0.01 & 2.682 & 0.82 & 1.21 & 99.4 & 1.97 \\
FL/S & 5033.5 & 806.69 & 5840.06 & 0.62 & 2.49 & 86.2 & 113.95 \\
DL/S & 10551.2 & 5.82 & 10557.1 & 0.57 & 1.39 & 99.9 & 178.5 \\
\hline
\end{tabular}

Table 21. Genetics $\left(\delta^{2} g\right)$, environment $\left(\delta^{2} e\right)$ and phenotypic $\left(\delta^{2} p\right)$ variations, phenotypic coefficient variance (PCV $(\%))$, broad sense heritability $\left(h^{2} b \%\right)$ and mean estimates for PH, SD, (NL), LA, DM, FY, DY, FL/S and DL/S during 2015 season

\begin{tabular}{cccccccc}
\hline Traits & $\delta^{2} g$ & $\delta^{2} \boldsymbol{e}$ & $\delta^{2} p$ & GCV & PCV \% & $\mathbf{h}^{\mathbf{2}} \mathbf{b} \%$ & mean \\
\hline PH & 524.4 & 2.26 & 526.63 & 0.21 & 1.38 & 99.5 & 108.48 \\
SD & 45.15 & 0.42 & 45.57 & 0.51 & 4.99 & 99.1 & 13.02 \\
NL/Plant & 36.79 & 0.66 & 37.45 & 0.56 & 7.58 & 98.23 & 10.75 \\
DM & 13.19 & 0.02 & 13.22 & 0.18 & 0.82 & 99.8 & 19.8 \\
FY & 38.25 & 0.01 & 38.27 & 0.64 & 1.11 & 99.9 & 9.60 \\
DY & 2.61 & 0.04 & 2.65 & 0.71 & 10.57 & 98.4 & 2.27 \\
FL/S & 924.5 & 6.59 & 931.1 & 0.30 & 2.56 & 99.2 & 100.2 \\
DL/S & 12423.1 & 558.7 & 12981.8 & 0.63 & 13.29 & 95.6 & 177.7 \\
\hline
\end{tabular}


Table 22. Genetic correlation $\left(r_{G}\right)$ between plant height $(\mathrm{PH})$, stem diameter (SD), number of leaves (NL), $(\mathrm{LA}),(\mathrm{DW}),(\mathrm{FW}),(\mathrm{DL} / \mathrm{S})$ and $(\mathrm{FL} / \mathrm{S})$ in 2014 season

Correlations (2014)

\begin{tabular}{|c|c|c|c|c|c|c|c|c|c|c|}
\hline & & PH & SD & LEAVES/PL & $\begin{array}{c}\text { NO.OF } \\
\text { L/PL }\end{array}$ & LA & DW & FW & FL/STEM & DL/STEM \\
\hline \multirow[t]{3}{*}{$\mathrm{PH}$} & $\begin{array}{l}\text { Pearson } \\
\text { Correlation }\end{array}$ & 1 & $0.678^{* *}$ & $0.808^{* *}$ & $0.866^{* *}$ & $0.483^{* *}$ & $0.784^{* *}$ & $0.796^{* * *}$ & 0.126 & .106 \\
\hline & Sig. (2-tailed) & & 0.000 & 0.000 & 0.000 & 0.000 & 0.000 & 0.000 & 0.292 & 0.377 \\
\hline & $\mathrm{N}$ & 72 & 72 & 72 & 72 & 72 & 72 & 72 & 72 & 72 \\
\hline \multirow[t]{3}{*}{ SD } & $\begin{array}{l}\text { Pearson } \\
\text { Correlation }\end{array}$ & $0.678^{* *}$ & 1 & $0.851^{* *}$ & $0.726^{* *}$ & $0.449^{* *}$ & $0.851^{* *}$ & $0.849^{* * *}$ & $-0.370^{* *}$ & $-0.400^{* * *}$ \\
\hline & Sig. (2-tailed) & 0.000 & & 0.000 & 0.000 & 0.000 & 0.000 & 0.000 & 0.001 & 0.001 \\
\hline & $\mathrm{N}$ & 72 & 72 & 72 & 72 & 72 & 72 & 72 & 72 & 72 \\
\hline \multirow[t]{3}{*}{ LEAVES/PL } & $\begin{array}{l}\text { Pearson } \\
\text { Correlation }\end{array}$ & $0.808^{* *}$ & $0.851^{* *}$ & 1 & $0.919^{* * *}$ & $0.523^{* *}$ & $0.865^{* *}$ & $0.885^{* *}$ & $-0.192-$ & $-0.211-$ \\
\hline & Sig. (2-tailed) & 0.000 & 0.000 & & 0.000 & 0.000 & 0.000 & 0.000 & 0.107 & 0.075 \\
\hline & $\mathrm{N}$ & 72 & 72 & 72 & 72 & 72 & 72 & 72 & 72 & 72 \\
\hline \multirow[t]{3}{*}{ NO.OF L/PL } & $\begin{array}{l}\text { Pearson } \\
\text { Correlation }\end{array}$ & $0.866^{* *}$ & $0.726^{* *}$ & $0.919^{* *}$ & 1 & $0.568^{* *}$ & $0.763^{* *}$ & $0.798^{* *}$ & 0.035 & 0.059 \\
\hline & Sig. (2-tailed) & 0.000 & 0.000 & 0.000 & & 0.000 & 0.000 & 0.000 & 0.769 & 0.625 \\
\hline & $\mathrm{N}$ & 72 & 72 & 72 & 72 & 72 & 72 & 72 & 72 & 72 \\
\hline \multirow[t]{3}{*}{ LA } & $\begin{array}{l}\text { Pearson } \\
\text { Correlation }\end{array}$ & $0.483^{* *}$ & $0.449^{* *}$ & $0.523^{* *}$ & $0.568^{* * *}$ & 1 & $0.320^{* *}$ & $0.429^{* * *}$ & $-0.287^{*}$ & $-0.270^{*}$ \\
\hline & Sig. (2-tailed) & .000 & .000 & .000 & .000 & & .006 & .000 & .014 & .022 \\
\hline & $\mathrm{N}$ & 72 & 72 & 72 & 72 & 72 & 72 & 72 & 72 & 72 \\
\hline \multirow[t]{3}{*}{ DW } & $\begin{array}{l}\text { Pearson } \\
\text { Correlation }\end{array}$ & $0.784^{* *}$ & $0.851^{* *}$ & $0.865^{* *}$ & $0.763^{* *}$ & $0.320^{* *}$ & 1 & $0.990^{* *}$ & $-0.111-$ & $-0.153-$ \\
\hline & Sig. (2-tailed) & 0.000 & 0.000 & 0.000 & 0.000 & 0.006 & & 0.000 & 0.353 & 0.199 \\
\hline & $\mathrm{N}$ & 72 & 72 & 72 & 72 & 72 & 72 & 72 & 72 & 72 \\
\hline \multirow[t]{3}{*}{ FW } & $\begin{array}{l}\text { Pearson } \\
\text { Correlation }\end{array}$ & $0.796^{* *}$ & $0.849^{* *}$ & $0.885^{* *}$ & $0.798^{* * *}$ & $0.429^{* *}$ & $0.990^{* *}$ & 1 & $-0.138-$ & $-0.171-$ \\
\hline & Sig. (2-tailed) & 0.000 & 0.000 & 0.000 & 0.000 & 0.000 & 0.000 & & 0.248 & 0.150 \\
\hline & $\mathrm{N}$ & 72 & 72 & 72 & 72 & 72 & 72 & 72 & 72 & 72 \\
\hline \multirow[t]{3}{*}{ FL/STEM } & $\begin{array}{l}\text { Pearson } \\
\text { Correlation }\end{array}$ & 0.126 & $-0.370^{* * *}$ & $-0.192-$ & 0.035 & $-0.287^{*}$ & $-0.111-$ & $-0.138-$ & 1 & $0.936^{* *}$ \\
\hline & Sig. (2-tailed) & 0.292 & 0.001 & 0.107 & 0.769 & 0.014 & 0.353 & 0.248 & & 0.000 \\
\hline & $\mathrm{N}$ & 72 & 72 & 72 & 72 & 72 & 72 & 72 & 72 & 72 \\
\hline \multirow[t]{3}{*}{ DL/STEM } & $\begin{array}{l}\text { Pearson } \\
\text { Correlation }\end{array}$ & 0.106 & $-0.400^{* * *}$ & $-0.211-$ & 0.059 & $-0.270^{*}$ & $-0.153-$ & $-0.171-$ & $0.936^{* *}$ & 1 \\
\hline & Sig. (2-tailed) & 0.377 & 0.001 & 0.075 & 0.625 & 0.022 & 0.199 & 0.150 & 0.000 & \\
\hline & $\mathrm{N}$ & 72 & 72 & 72 & 72 & 72 & 72 & 72 & 72 & 72 \\
\hline
\end{tabular}

**. Correlation is significant at the 0.01 level (2-tailed).

*. Correlation is significant at the 0.05 level (2-tailed). 
Table 23. Genetic correlation $\left(\mathbf{r}_{\mathrm{G}}\right)$ between plant height $(\mathrm{PH})$, stem diameter (SD), number of leaves (NL), (LA), (DW), (FW), (DL/S) and (FL/S) in 2015 season

Correlations (2015)

\begin{tabular}{|c|c|c|c|c|c|c|c|c|c|c|}
\hline & & $\mathrm{pH}$ & SD & NL/P & $\mathrm{LA} / \mathrm{P}$ & $\mathrm{DM}$ & FY & DY & FL/S & $\mathrm{DL} / \mathrm{S}$ \\
\hline \multirow[t]{3}{*}{$\mathrm{pH}$} & Pearson Correlation & 1 & $0.870^{* *}$ & $0.804^{* *}$ & $0.882^{* * *}$ & $0.343^{* *}$ & $0.859^{* *}$ & $0.453^{* *}$ & $-0.022-$ & 0.144 \\
\hline & Sig. (2-tailed) & & 0.000 & 0.000 & 0.000 & 0.003 & 0.000 & 0.000 & 0.854 & 0.231 \\
\hline & $\mathrm{N}$ & 71 & 71 & 71 & 71 & 71 & 71 & 71 & 71 & 71 \\
\hline \multirow[t]{3}{*}{ SD } & Pearson Correlation & $0.870^{* *}$ & 1 & $0.877^{* *}$ & $0.857^{* *}$ & $0.538^{* *}$ & $0.861^{* *}$ & $0.474^{* *}$ & $-0.204-$ & $-0.027-$ \\
\hline & Sig. (2-tailed) & 0.000 & & 0.000 & 0.000 & 0.000 & 0.000 & 0.000 & 0.088 & 0.823 \\
\hline & $\mathrm{N}$ & 71 & 71 & 71 & 71 & 71 & 71 & 71 & 71 & 71 \\
\hline \multirow[t]{3}{*}{$\mathrm{NL} / \mathrm{P}$} & Pearson Correlation & $0.804^{* *}$ & $0.877^{* *}$ & 1 & $0.900^{* *}$ & $0.601^{* *}$ & $0.753^{* *}$ & $0.357^{* *}$ & $-0.248^{*}$ & $-0.020-$ \\
\hline & Sig. (2-tailed) & 0.000 & 0.000 & & 0.000 & 0.000 & 0.000 & 0.002 & 0.037 & 0.870 \\
\hline & $\mathrm{N}$ & 71 & 71 & 71 & 71 & 71 & 71 & 71 & 71 & 71 \\
\hline \multirow[t]{3}{*}{$\mathrm{LA} / \mathrm{P}$} & Pearson Correlation & $0.882^{* *}$ & $0.857^{* *}$ & $0.900^{* *}$ & 1 & $0.365^{* *}$ & $0.817^{* *}$ & $0.389^{* *}$ & 0.054 & $0.293^{*}$ \\
\hline & Sig. (2-tailed) & 0.000 & 0.000 & 0.000 & & 0.002 & 0.000 & 0.001 & 0.655 & 0.013 \\
\hline & $\mathrm{N}$ & 71 & 71 & 71 & 71 & 71 & 71 & 71 & 71 & 71 \\
\hline \multirow[t]{3}{*}{$\mathrm{DM}$} & Pearson Correlation & $0.343^{* *}$ & $0.538^{* *}$ & $0.601^{* *}$ & $0.365^{* *}$ & 1 & $0.234^{*}$ & 0.052 & $0.489^{* *}$ & $-0.301^{*}$ \\
\hline & Sig. (2-tailed) & 0.003 & 0.000 & 0.000 & 0.002 & & 0.050 & 0.665 & 0.000 & 0.011 \\
\hline & $\mathrm{N}$ & 71 & 71 & 71 & 71 & 71 & 71 & 71 & 71 & 71 \\
\hline \multirow[t]{3}{*}{ FY } & Pearson Correlation & $0.859^{* *}$ & $0.861^{* *}$ & $0.753^{* *}$ & $0.817^{* *}$ & $0.234^{*}$ & 1 & $0.475^{* *}$ & $-0.106-$ & $-0.024-$ \\
\hline & Sig. (2-tailed) & 0.000 & 0.000 & 0.000 & 0.000 & 0.050 & & 0.000 & 0.381 & 0.845 \\
\hline & $\mathrm{N}$ & 71 & 71 & 71 & 71 & 71 & 71 & 71 & 71 & 71 \\
\hline \multirow[t]{3}{*}{ DY } & Pearson Correlation & $0.453^{* *}$ & $0.474^{* *}$ & $0.357^{* *}$ & $0.389^{* *}$ & 0.052 & $0.475^{* *}$ & 1 & $-0.146-$ & $-0.077-$ \\
\hline & Sig. (2-tailed) & .000 & .000 & .002 & .001 & .665 & .000 & & .223 & .525 \\
\hline & $\mathrm{N}$ & 71 & 71 & 71 & 71 & 71 & 71 & 71 & 71 & 71 \\
\hline \multirow[t]{3}{*}{ FL/S\% } & Pearson Correlation & $-0.022-$ & $-0.204-$ & $-0.248^{*}$ & 0.054 & $-0.489^{* *}$ & $-0.106-$ & $-0.146-$ & 1 & $0.833^{* *}$ \\
\hline & Sig. (2-tailed) & 0.854 & 0.088 & 0.037 & 0.655 & 0.000 & 0.381 & 0.223 & & 0.000 \\
\hline & $\mathrm{N}$ & 71 & 71 & 71 & 71 & 71 & 71 & 71 & 71 & 71 \\
\hline \multirow[t]{3}{*}{$\mathrm{DL} / \mathrm{S} \%$} & Pearson Correlation & 0.144 & $-0.027-$ & $-0.020-$ & $0.293^{*}$ & $-0.301^{*}$ & $-0.024-$ & $-0.077-$ & $0.833^{* *}$ & 1 \\
\hline & Sig. (2-tailed) & 0.231 & 0.823 & 0.870 & 0.013 & 0.011 & 0.845 & 0.525 & 0.000 & \\
\hline & $\mathrm{N}$ & 71 & 71 & 71 & 71 & 71 & 71 & 71 & 71 & 71 \\
\hline
\end{tabular}

**. Correlation is significant at the 0.01 level (2-tailed).

*. Correlation is significant at the 0.05 level (2-tailed).

On the other hand, less similarity was found between G1 and G7. Therefore, there is a diversity among the genotypes. Cluster analysis is considered a valuable tool for subdividing the number of genotypes in groups in clouding similarity and dissimilarity genotypes.

The genotypes might be classified into three distinguished groups, Also, it might help in breeding programs. These results are in agreement with Gad, Ehak, et al. (1988) Sultan et al. (2016)and Khatab et al. (2016). Figures (1, 2 and 3) and Table (34) illustrates the total soluble protein fractions of teosinte genotypes.
$100,81,69,66,52,42,37.2$ and $34 \mathrm{KDa}$ protein bands were common between G1 and G2. On the other hand, 107, 77, 63, 50, 47, 41, 39.5, 39, 34.5 and $34 \mathrm{KDa}$, were recorded as common protein fragments between G3 and G4. Interestingly, 107, 77, 63, 50, 47, 45, 40, $39.5,39,37,34.5,34$ and $29 \mathrm{KDa}$ were in common between G5 and G6. Moreover, 117, 88, 63, 44 and 38.5 KDa were in common between G7 and G8 as shown in Table (34).

As a result for genetic similarity it was clarified for teosinte genotypes, based on total soluble protein fractionation via SDS - PAGE techiique. As shown in 
Figure (5), G2 of teosinte showed a high dissimilarity and located in separate individual cluster.

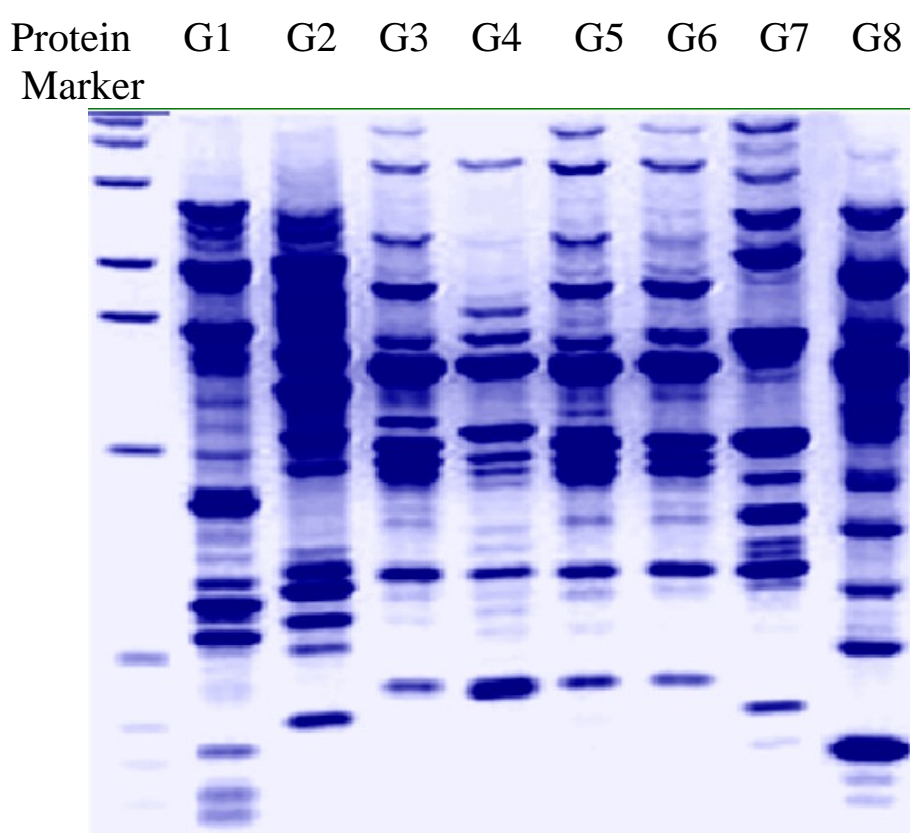

Figure 1. Protein fingerprinting patterns foe eight teosinte genotypes

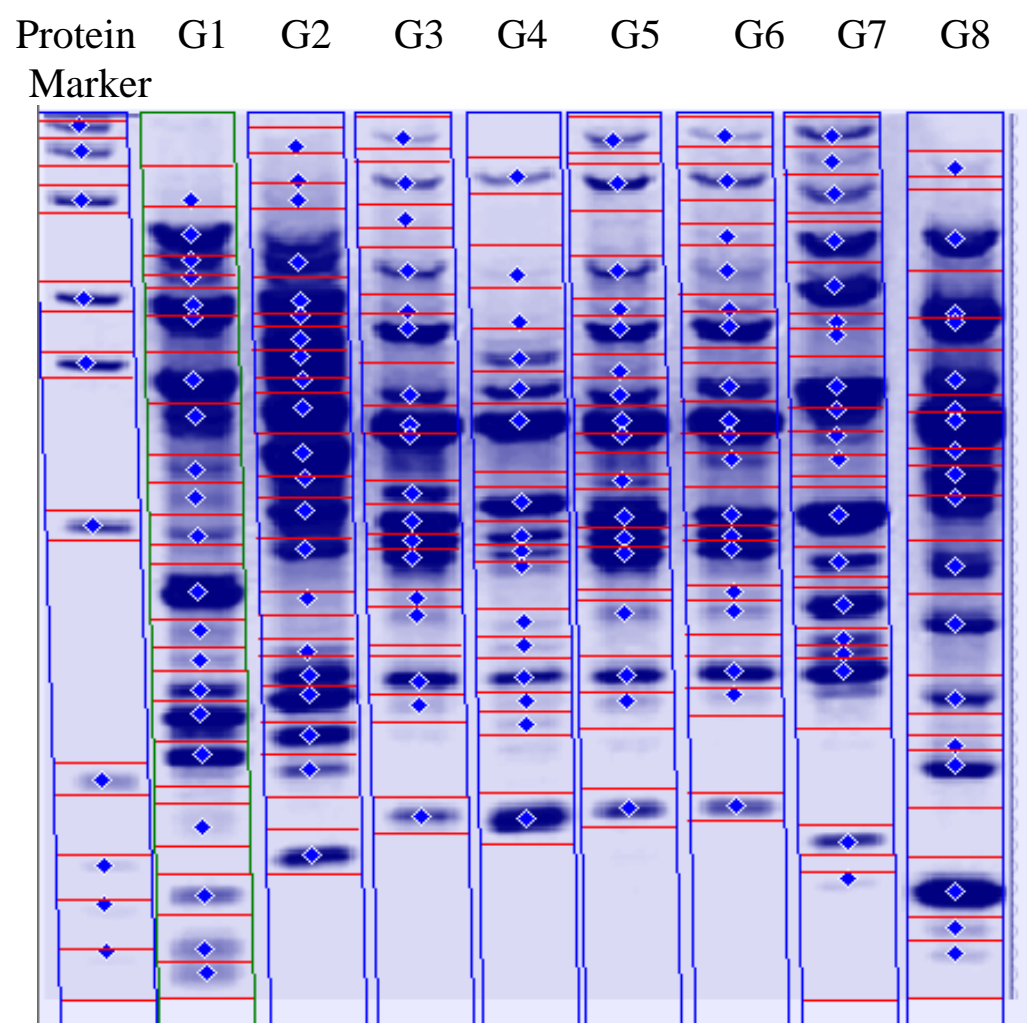

Figure 2. Computerized detection for protein patterns for eight teosinte genotypes 


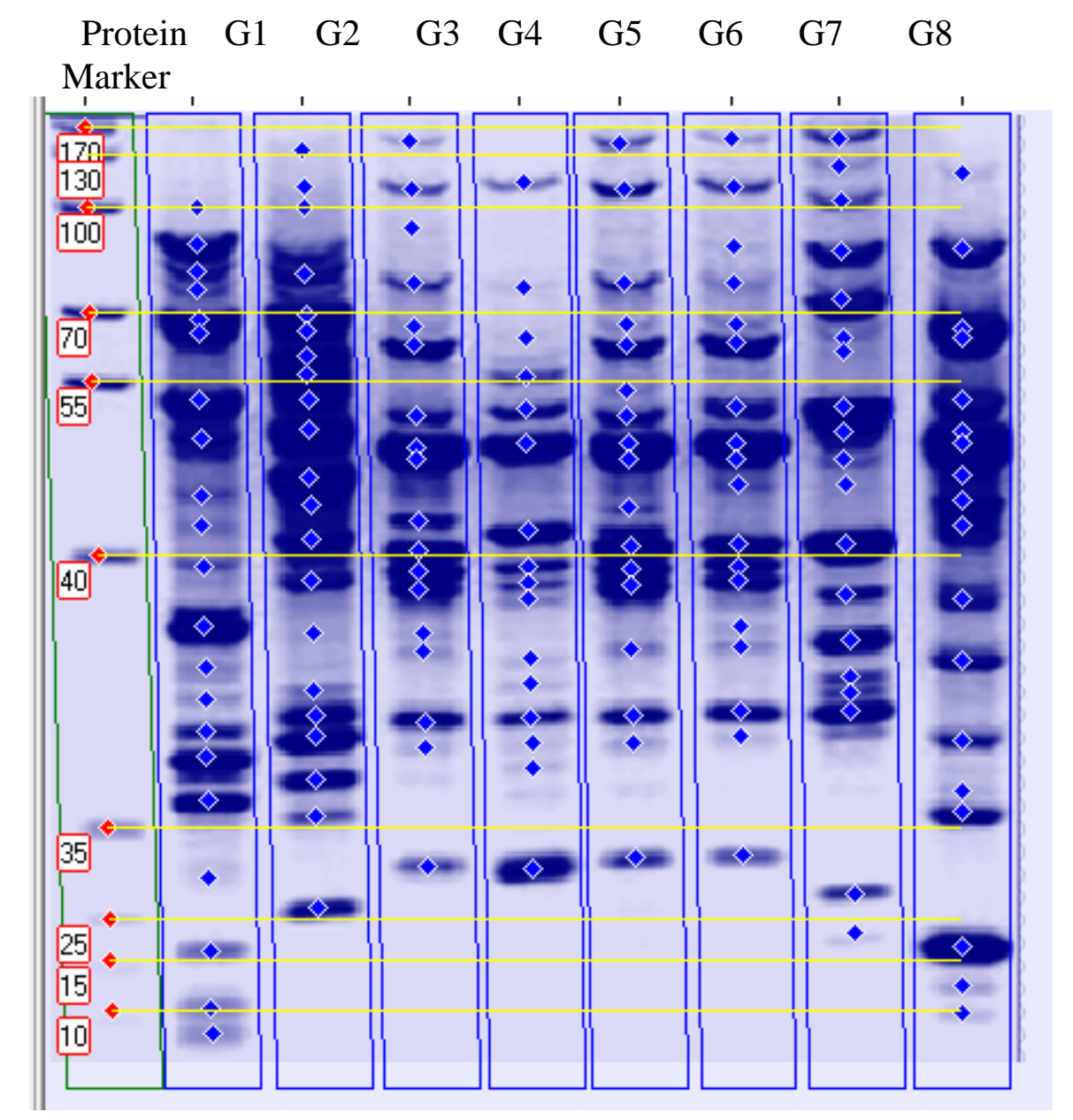

Figure 3. Computerized detection of molecular weight for eight teosinte genotypes

Table 24.Data analysis of protein patterns parameters for protein marker

\begin{tabular}{llllllll}
\hline Band No & Position & Peak Height & Area & Band \% & Lane \% & MW & Rf \\
\hline 1 & 6 & 105.42 & 266.00 & 8.02 & 4.72 & 170.000 & 0.016 \\
2 & 17 & 103.66 & 456.00 & 10.30 & 6.07 & 130.000 & 0.044 \\
3 & 38 & 141.55 & 456.00 & 12.43 & 7.32 & 100.000 & 0.098 \\
4 & 79 & 157.24 & 494.00 & 14.74 & 8.68 & 70.000 & 0.204 \\
5 & 107 & 170.16 & 418.00 & 14.63 & 8.61 & 55.000 & 0.276 \\
6 & 176 & 127.16 & 494.00 & 12.17 & 7.16 & 40.000 & 0.455 \\
7 & 284 & 63.37 & 494.00 & 8.53 & 5.02 & 35.000 & 0.734 \\
8 & 320 & 29.84 & 722.00 & 6.45 & 3.79 & 25.000 & 0.827 \\
9 & 337 & 19.71 & 798.00 & 6.51 & 3.83 & 15.000 & 0.871 \\
10 & 357 & 17.47 & 836.00 & 6.22 & 3.66 & 10.000 & 0.922 \\
\hline
\end{tabular}


Table 25. Data analysis of protein patterns parameters for the first teosinte genotype

\begin{tabular}{lccccccc}
\hline Band No & Position & Peak Height & Area & Band \% & Lane \% & MW & Rf \\
\hline 1 & 38 & 38.18 & 646.00 & 1.47 & 1.41 & 100.000 & 0.098 \\
2 & 52 & 204.16 & 798.00 & 7.95 & 7.63 & 89.511 & 0.134 \\
3 & 63 & 167.50 & 304.00 & 3.55 & 3.40 & 81.224 & 0.163 \\
4 & 70 & 136.71 & 228.00 & 2.21 & 2.12 & 76.135 & 0.181 \\
5 & 82 & 219.14 & 456.00 & 6.29 & 6.04 & 68.090 & 0.212 \\
6 & 88 & 202.42 & 570.00 & 6.73 & 6.46 & 64.490 & 0.227 \\
7 & 114 & 222.16 & 836.00 & 10.87 & 10.43 & 52.219 & 0.295 \\
8 & 129 & 187.37 & 836.00 & 9.64 & 9.25 & 47.426 & 0.333 \\
9 & 152 & 133.39 & 456.00 & 3.89 & 3.73 & 42.637 & 0.393 \\
10 & 164 & 103.29 & 494.00 & 3.36 & 3.23 & 41.085 & 0.424 \\
11 & 180 & 127.76 & 494.00 & 3.52 & 3.38 & 39.118 & 0.465 \\
12 & 204 & 214.34 & 912.00 & 10.41 & 9.99 & 38.617 & 0.527 \\
13 & 220 & 82.34 & 456.00 & 2.36 & 2.27 & 38.217 & 0.568 \\
14 & 233 & 72.39 & 380.00 & 1.59 & 1.53 & 37.927 & 0.602 \\
15 & 246 & 171.26 & 456.00 & 3.50 & 3.36 & 37.556 & 0.636 \\
16 & 256 & 214.50 & 684.00 & 7.99 & 7.66 & 37.148 & 0.661 \\
17 & 273 & 206.05 & 722.00 & 6.27 & 6.02 & 36.061 & 0.105 \\
18 & 304 & 30.55 & 684.00 & 1.40 & 1.34 & 31.478 & 0.186 \\
19 & 333 & 100.39 & 646.00 & 2.33 & 2.24 & 17.090 & 0.860 \\
20 & 356 & 80.18 & 760.00 & 2.57 & 2.47 & 10.142 & 0.920 \\
21 & 366 & 70.47 & 608.00 & 2.11 & 2.03 & 7750 & 0.946 \\
\hline & & & & & & \\
\hline
\end{tabular}

Table 26. Data analysis of protein patterns parameters for the second teosinte genotype

\begin{tabular}{cccccccc}
\hline Band No & Position & Peak Height & Area & Band \% & Lane \% & MW & Rf \\
\hline 1 & 15 & 36.39 & 418.00 & 0.80 & 0.77 & 136.136 & 0.039 \\
2 & 29 & 50.61 & 456.00 & 1.13 & 1.09 & 107.620 & 0.075 \\
3 & 38 & 66.61 & 418.00 & 1.60 & 1.53 & 100.000 & 0.098 \\
4 & 64 & 192.42 & 1102.00 & 9.67 & 9.27 & 80.485 & 0.165 \\
5 & 80 & 228.45 & 608.00 & 7.75 & 7.43 & 69.355 & 0.207 \\
6 & 87 & 215.66 & 190.00 & 2.52 & 242 & 65.070 & 0.225 \\
7 & 97 & 223.84 & 380.00 & 5.12 & 4.91 & 59.636 & 0.251 \\
8 & 104 & 221.03 & 456.00 & 6.27 & 6.01 & 56.308 & 0.269 \\
9 & 114 & 215.05 & 228.00 & 3.02 & 2.90 & 52.219 & 0.295 \\
10 & 126 & 231.74 & 684.00 & 9.37 & 8.98 & 48.267 & 0.326 \\
11 & 145 & 232.47 & 684.00 & 9.35 & 8.96 & 43.813 & 0.375 \\
12 & 156 & 202.74 & 342.00 & 4.17 & 4.00 & 42.059 & 0.403 \\
13 & 169 & 216.53 & 646.00 & 7.91 & 7.59 & 40.584 & 0.437 \\
14 & 186 & 197.82 & 874.00 & 6.84 & 6.56 & 39.357 & 0.481 \\
15 & 207 & 69.18 & 380.00 & 1.52 & 1.46 & 38.530 & 0.535 \\
16 & 229 & 104.79 & 266.00 & 1.36 & 1.30 & 38.020 & 0.592 \\
17 & 239 & 207.79 & 494.00 & 5.05 & 4.84 & 37.773 & 0.618 \\
18 & 248 & 221.29 & 570.00 & 5.89 & 5.64 & 37.485 & 0.641 \\
19 & 265 & 205.00 & 532.00 & 4.50 & 4.31 & 36.645 & 0.685 \\
20 & 279 & 129.82 & 684.00 & 2.68 & 2.57 & 35.523 & 0.721 \\
21 & 316 & 181.71 & 722.00 & 3.48 & 3.34 & 27.058 & 0.817
\end{tabular}

High genetic similarity was found within $3,4,5,6$ and 7 genotypes of teosinte.

SDS - PAGE technique, as an accurate indicator methodology, added more support for diagnosis different of microflora in clover by Liu et al. (2007) Morover, Azab et al. (2011) added more support to the presented results Via SDS - PAGE analysis for the water doluble protein in the six Egyptian clover. It revealed a total number of $\mathrm{Lg}$ band $\mathrm{S}$, with molecular 
weights (MW), ranging from about 12-24 to 121.2 much be uniquely identified with genotype protein $\mathrm{KDa}$, and these six Egyptian clover genotypes could markers.

Table 27. Data analysis of protein patterns parameters for the third teosinte genotype

\begin{tabular}{cccccccc}
\hline Band No & Position & Peak Height & Area & Band \% & Lane \% & MW & Rf \\
\hline 1 & 11 & 55.21 & 532.00 & 1.65 & 1.52 & 150.303 & 0.028 \\
2 & 30 & 109.71 & 684.00 & 3.51 & 3.22 & 106.561 & 0.078 \\
3 & 46 & 41.26 & 380.00 & 1.35 & 1.24 & 94.055 & 0.119 \\
4 & 68 & 137.50 & 760.00 & 6.03 & 5.53 & 77.567 & 0.176 \\
5 & 85 & 85.74 & 304.00 & 2.29 & 2.10 & 66.254 & 0.220 \\
6 & 92 & 203.53 & 798.00 & 10.18 & 9.34 & 62.253 & 0.238 \\
7 & 120 & 191.42 & 684.00 & 8.81 & 8.08 & 50.120 & 0.310 \\
8 & 133 & 230.34 & 456.00 & 9.35 & 8.58 & 46.390 & 0.344 \\
9 & 138 & 219.97 & 760.00 & 12.50 & 11.47 & 45.224 & 0.357 \\
10 & 162 & 191.97 & 380.00 & 5.83 & 5.35 & 41.308 & 0.419 \\
11 & 174 & 216.18 & 456.00 & 8.19 & 7.52 & 40.154 & 0.450 \\
12 & 182 & 213.42 & 266.00 & 5.35 & 4.91 & 39.590 & 0.470 \\
13 & 189 & 197.50 & 646.00 & 8.96 & 8.22 & 39.201 & 0.488 \\
14 & 207 & 65.00 & 266.00 & 1.60 & 1.46 & 38.530 & 0.535 \\
15 & 214 & 69.58 & 646.00 & 3.03 & 2.78 & 38.352 & 0.553 \\
16 & 242 & 188.55 & 646.00 & 6.41 & 5.88 & 37.686 & 0.625 \\
17 & 252 & 45.18 & 418.00 & 1.50 & 1.38 & 37.328 & 0.651 \\
18 & 299 & 123.87 & 608.00 & 3.47 & 3.19 & 32.698 & 0.773 \\
\hline
\end{tabular}

Table 28. Data analysis of protein patterns parameters for the fourth teosinte genotype

\begin{tabular}{cccccccc}
\hline Band No & Position & Peak Height & Area & Band \% & Lane \% & MW & Rf \\
\hline 1 & 28 & 94.39 & 608.00 & 3.29 & 2.88 & 108.766 & 0.072 \\
2 & 69 & 43.55 & 684.00 & 2.84 & 2.48 & 76.848 & 0.178 \\
3 & 89 & 49.11 & 646.00 & 3.28 & 2.87 & 63.919 & 0.230 \\
4 & 105 & 150.21 & 684.00 & 7.54 & 6.60 & 55.864 & 0.271 \\
5 & 118 & 203.05 & 532.00 & 8.87 & 7.76 & 50.792 & 0.305 \\
6 & 131 & 236.82 & 1102.00 & 21.99 & 19.25 & 46.896 & 0.339 \\
7 & 166 & 229.21 & 570.00 & 11.97 & 10.48 & 40.876 & 0.429 \\
8 & 180 & 202.34 & 380.00 & 7.02 & 6.14 & 39.718 & 0.465 \\
9 & 187 & 158.32 & 266.00 & 4.26 & 3.73 & 39.303 & 0.483 \\
10 & 193 & 96.63 & 760.00 & 5.18 & 4.53 & 39.016 & 0.499 \\
11 & 217 & 48.42 & 456.00 & 2.15 & 1.88 & 38.283 & 0.561 \\
12 & 227 & 50.29 & 342.00 & 1.67 & 1.46 & 38.065 & 0.587 \\
13 & 240 & 177.39 & 570.00 & 6.27 & 5.49 & 37.745 & 0.620 \\
14 & 250 & 40.37 & 304.00 & 1.40 & 1.23 & 37.409 & 0.646 \\
15 & 260 & 41.66 & 380.00 & 1.56 & 1.37 & 36.943 & 0.672 \\
16 & 300 & 199.37 & 836.00 & 10.71 & 9.38 & 32.478 & 0.775 \\
\hline
\end{tabular}


Table 29. Data analysis of protein patterns parameters for the fifth teosinte genotype

\begin{tabular}{cccccccc}
\hline Band No & Position & Peak Height & Area & Band \% & Lane \% & MW & Rf \\
\hline 1 & 12 & 99.79 & 608.00 & 3.07 & 2.64 & 146.572 & 0.031 \\
2 & 30 & 156.00 & 760.00 & 5.57 & 4.78 & 106.561 & 0.078 \\
3 & 68 & 14242 & 684.00 & 640 & 5.50 & 77.567 & 0.176 \\
4 & 84 & 86.37 & 304.00 & 2.36 & 2.03 & 66.858 & 0.217 \\
5 & 92 & 189.89 & 608.00 & 8.31 & 7.13 & 62.253 & 0.238 \\
6 & 110 & 100.61 & 380.00 & 3.60 & 3.09 & 53.763 & 0.284 \\
7 & 120 & 192.84 & 456.00 & 6.97 & 5.99 & 50.120 & 0.310 \\
8 & 131 & 226.37 & 456.00 & 9.81 & 8.43 & 46.896 & 0.339 \\
9 & 138 & 212.03 & 304.00 & 5.98 & 5.14 & 45.224 & 0.357 \\
10 & 157 & 143.29 & 228.00 & 3.04 & 2.61 & 41.925 & 0.406 \\
11 & 172 & 219.68 & 646.00 & 12.01 & 10.31 & 40.318 & 0.444 \\
12 & 181 & 209.87 & 304.00 & 6.34 & 5.44 & 39.653 & 0.468 \\
13 & 188 & 200.84 & 684.00 & 9.90 & 8.50 & 39.251 & 0.486 \\
14 & 213 & 83.84 & 874.00 & 4.39 & 3.77 & 38.375 & 0.550 \\
15 & 239 & 181.42 & 608.00 & 6.09 & 5.23 & 37.773 & 0.618 \\
16 & 250 & 56.68 & 570.00 & 2.06 & 1.77 & 37.409 & 0.646 \\
17 & 296 & 137.26 & 608.00 & 4.08 & 3.50 & 33.296 & 0.765 \\
\hline
\end{tabular}

Table 30. Data analysis of protein patterns parameters for the sixth teosinte genotype

\begin{tabular}{cccccccc} 
Band No & Position & Peak Height & Area & Band \% & Lane \% & MW & Rf \\
1 & 10 & 66.55 & 494.00 & 2.03 & 1.79 & 154.128 & 0.026 \\
2 & 29 & 137.97 & 608.00 & 4.57 & 4.02 & 107.620 & 0.075 \\
3 & 53 & 56.39 & 342.00 & 1.81 & 1.59 & 88.751 & 0.137 \\
4 & 68 & 95.84 & 798.00 & 6.02 & 5.30 & 77.567 & 0.176 \\
5 & 84 & 101.97 & 266.00 & 2.43 & 2.14 & 66.858 & 0.217 \\
6 & 91 & 210.89 & 570.00 & 9.20 & 8.09 & 62.800 & 0.235 \\
7 & 117 & 195.66 & 608.00 & 9.11 & 8.01 & 51.138 & 0.302 \\
8 & 131 & 235.42 & 532.00 & 11.53 & 10.15 & 46.896 & 0.339 \\
9 & 138 & 205.47 & 304.00 & 5.62 & 4.94 & 45.224 & 0.357 \\
10 & 148 & 146.74 & 532.00 & 6.61 & 5.82 & 43.282 & 0.382 \\
11 & 171 & 222.32 & 646.00 & 10.25 & 9.02 & 40.404 & 0.442 \\
12 & 180 & 209.82 & 228.00 & 4.11 & 4.15 & 39.718 & 0.465 \\
13 & 186 & 210.00 & 722.00 & 10.02 & 8.81 & 39.357 & 0.481 \\
14 & 204 & 65.42 & 266.00 & 1.65 & 1.45 & 38.617 & 0.527 \\
15 & 212 & 84.05 & 532.00 & 3.14 & 2.16 & 38.400 & 0.548 \\
16 & 238 & 200.16 & 532.00 & 6.59 & 5.80 & 37.800 & 0.615 \\
17 & 248 & 44.55 & 456.00 & 1.54 & 1.35 & 37.485 & 0.641 \\
18 & 295 & 119.03 & 456.00 & 3.18 & 2.80 & 33.476 & 0.162 \\
\hline
\end{tabular}


Table 31. Data analysis of protein patterns parameters for the seventh teosinte genotype

\begin{tabular}{cccccccc}
\hline Band No & Position & Peak Height & Area & Band \% & Lane \% & MW & Rf \\
\hline 1 & 10 & 146.87 & 494.00 & 3.52 & 3.34 & 154.128 & 0.026 \\
2 & 21 & 81.29 & 456.00 & 246 & 2.34 & 120.070 & 0.054 \\
3 & 35 & 131.82 & 608.00 & 4.33 & 4.12 & 102.214 & 0.090 \\
4 & 55 & 196.45 & 646.00 & 7.25 & 6.89 & 87.234 & 0.142 \\
5 & 74 & 207.95 & 836.00 & 10.35 & 9.84 & 73.341 & 0.191 \\
6 & 89 & 118.47 & 228.00 & 2.00 & 1.90 & 63.919 & 0.230 \\
7 & 95 & 98.24 & 456.00 & 3.32 & 3.16 & 60.659 & 0.245 \\
8 & 117 & 230.61 & 836.00 & 11.21 & 10.66 & 51.138 & 0.302 \\
9 & 127 & 204.89 & 380.00 & 5.30 & 5.04 & 47.980 & 0.328 \\
10 & 138 & 140.50 & 380.00 & 3.58 & 3.40 & 45.224 & 0.357 \\
11 & 148 & 97.21 & 342.00 & 2.49 & 2.37 & 43.282 & 0.382 \\
12 & 171 & 233.32 & 988.00 & 12.44 & 11.83 & 40.404 & 0.442 \\
13 & 191 & 186.32 & 494.00 & 5.06 & 4.81 & 39.105 & 0.494 \\
14 & 209 & 208.89 & 646.00 & 7.40 & 7.04 & 38.476 & 0.540 \\
15 & 224 & 143.50 & 304.00 & 65 & 2.50 & 38.130 & 0.579 \\
16 & 230 & 216.03 & 190.00 & 1.98 & 1.88 & 37.998 & 0.594 \\
17 & 238 & 148.76 & 1140.00 & 9.00 & 8.55 & 37.800 & 0.615 \\
18 & 310 & 142.14 & 494.00 & 2.19 & 2.65 & 29.566 & 0.801 \\
19 & 326 & 24.45 & 2090.00 & 2.89 & 2.15 & 21.382 & 0.842 \\
\hline
\end{tabular}

Table 32. Data analysis of protein patterns parameters for the eighth teosinte genotype

\begin{tabular}{cccccccc}
\hline Band No & Position & Peak Height & Area & Band \% & Lane \% & MW & Rf \\
\hline 1 & 24 & 46.74 & 418.00 & 1.12 & 1.09 & 114.421 & 0.062 \\
2 & 54 & 182.05 & 1330.00 & 9.29 & 8.99 & 87.992 & 0.140 \\
3 & 86 & 214.18 & 760.00 & 8.27 & 8.00 & 65.658 & 0.222 \\
4 & 89 & 209.79 & 494.00 & 6.12 & 5.92 & 63.919 & 0.230 \\
5 & 114 & 195.42 & 722.00 & 8.41 & 8.14 & 52.219 & 0.295 \\
6 & 127 & 225.16 & 304.00 & 4.31 & 4.17 & 47.980 & 0.328 \\
7 & 131 & 230.18 & 570.00 & 8.71 & 8.43 & 46.896 & 0.339 \\
8 & 144 & 195.42 & 266.00 & 3.48 & 3.36 & 44.000 & 0.372 \\
9 & 154 & 202.92 & 494.00 & 6.60 & 6.39 & 42.340 & 0.398 \\
10 & 164 & 188.79 & 722.00 & 7.31 & 7.07 & 41.085 & 0.424 \\
11 & 193 & 170.95 & 874.00 & 7.44 & 7.20 & 39.016 & 0.499 \\
12 & 218 & 189.16 & 1292.00 & 8.37 & 8.10 & 38.261 & 0.563 \\
13 & 249 & 167.42 & 646.00 & 4.11 & 3.97 & 37.448 & 0.643 \\
14 & 269 & 50.55 & 228.00 & 0.72 & 0.70 & 36.371 & 0.695 \\
15 & 278 & 191.50 & 950.00 & 5.02 & 4.86 & 35.619 & 0.718 \\
16 & 331 & 230.82 & 950.00 & 8.18 & 7.91 & 18.266 & 0.855 \\
17 & 347 & 54.50 & 380.00 & 1.08 & 1.04 & 11.689 & 0.897 \\
18 & 358 & 41.47 & 950.00 & 1.47 & 1.42 & 9.750 & 0.925 \\
\hline
\end{tabular}


Table 33. Data matrix for eight teosinte genotypes

\begin{tabular}{|c|c|c|c|c|c|c|c|c|c|}
\hline Name & MW & Lane2 & Lane3 & Lane4 & Lane5 & Lane6 & Lane7 & Lane8 & Lane9 \\
\hline Band1 & 151.283 & 0 & 0 & 1 & 0 & 1 & 1 & 1 & 0 \\
\hline Band2 & 136.136 & 0 & 1 & 0 & 0 & 0 & 0 & 0 & 0 \\
\hline Band3 & 117.245 & 0 & 0 & 0 & 0 & 0 & 0 & 1 & 1 \\
\hline Band4 & 107.425 & 0 & 1 & 1 & 1 & 1 & 1 & 0 & 0 \\
\hline Band5 & 100.738 & 1 & 1 & 0 & 0 & 0 & 0 & 1 & 0 \\
\hline Band6 & 94.055 & 0 & 0 & 0 & 0 & 0 & 0 & 0 & 0 \\
\hline Band7 & 88.372 & 1 & 0 & 0 & 0 & 0 & 1 & 1 & 1 \\
\hline Band8 & 80.855 & 1 & 1 & 0 & 0 & 0 & 0 & 0 & 0 \\
\hline Band9 & 77.137 & 1 & 0 & 1 & 1 & 1 & 1 & 0 & 0 \\
\hline Band10 & 73.341 & 0 & 0 & 0 & 0 & 0 & 0 & 1 & 0 \\
\hline Band11 & 68.723 & 1 & 1 & 0 & 0 & 0 & 0 & 0 & 0 \\
\hline Band12 & 65.865 & 1 & 1 & 1 & 0 & 1 & 1 & 0 & 1 \\
\hline Band13 & 63.177 & 0 & 0 & 1 & 1 & 1 & 1 & 1 & 1 \\
\hline Band14 & 60.147 & 0 & 1 & 0 & 0 & 0 & 0 & 1 & 0 \\
\hline Band15 & 56.086 & 0 & 1 & 0 & 1 & 0 & 0 & 0 & 0 \\
\hline Band16 & 53.763 & 0 & 0 & 0 & 0 & 1 & 0 & 0 & 0 \\
\hline Band17 & 52.219 & 1 & 1 & 0 & 0 & 0 & 0 & 0 & 0 \\
\hline Band18 & 50.662 & 0 & 0 & 1 & 1 & 1 & 1 & 1 & 0 \\
\hline Band19 & 48.076 & 0 & 1 & 0 & 0 & 0 & 0 & 1 & 1 \\
\hline Band20 & 46.900 & 1 & 0 & 1 & 1 & 1 & 1 & 0 & 1 \\
\hline Band21 & 45.224 & 0 & 0 & 1 & 0 & 1 & 1 & 1 & 0 \\
\hline Band22 & 43.594 & 0 & 1 & 0 & 0 & 0 & 1 & 1 & 1 \\
\hline Band23 & 42.240 & 1 & 1 & 0 & 0 & 1 & 0 & 0 & 1 \\
\hline Band24 & 41.088 & 1 & 0 & 1 & 1 & 0 & 0 & 0 & 1 \\
\hline Band25 & 40.373 & 0 & 1 & 1 & 0 & 1 & 1 & 1 & 0 \\
\hline Band26 & 39.680 & 1 & 0 & 1 & 1 & 1 & 1 & 0 & 0 \\
\hline Band27 & 39.294 & 0 & 1 & 1 & 1 & 1 & 1 & 0 & 0 \\
\hline Band28 & 39.046 & 0 & 0 & 0 & 1 & 0 & 0 & 1 & 1 \\
\hline Band29 & 38.554 & 1 & 1 & 1 & 0 & 0 & 1 & 1 & 0 \\
\hline Band30 & 38.376 & 0 & 0 & 1 & 0 & 1 & 1 & 0 & 0 \\
\hline Band31 & 38.253 & 1 & 0 & 0 & 1 & 0 & 0 & 0 & 1 \\
\hline Band32 & 38.130 & 0 & 0 & 0 & 0 & 0 & 0 & 1 & 0 \\
\hline Band33 & 38.028 & 0 & 1 & 0 & 1 & 0 & 0 & 1 & 0 \\
\hline Band34 & 37.927 & 1 & 0 & 0 & 0 & 0 & 0 & 0 & 0 \\
\hline Band35 & 37.763 & 0 & 1 & 1 & 1 & 1 & 1 & 1 & 0 \\
\hline Band36 & 37.446 & 1 & 1 & 1 & 1 & 1 & 1 & 0 & 1 \\
\hline Band37 & 37.148 & 1 & 0 & 0 & 0 & 0 & 0 & 0 & 0 \\
\hline Band38 & 36.943 & 0 & 0 & 0 & 1 & 0 & 0 & 0 & 0 \\
\hline Band39 & 36.645 & 0 & 1 & 0 & 0 & 0 & 0 & 0 & 0 \\
\hline Band40 & 36.371 & 0 & 0 & 0 & 0 & 0 & 0 & 0 & 1 \\
\hline Band41 & 36.061 & 1 & 0 & 0 & 0 & 0 & 0 & 0 & 0 \\
\hline Band42 & 35.571 & 0 & 1 & 0 & 0 & 0 & 0 & 0 & 1 \\
\hline Band43 & 33.386 & 0 & 0 & 0 & 0 & 1 & 1 & 0 & 0 \\
\hline Band44 & 32.588 & 0 & 0 & 1 & 1 & 0 & 0 & 0 & 0 \\
\hline Band45 & 31.478 & 1 & 0 & 0 & 0 & 0 & 0 & 0 & 0 \\
\hline Band46 & 29.566 & 0 & 0 & 0 & 0 & 0 & 0 & 1 & 0 \\
\hline Band47 & 27.058 & 0 & 1 & 0 & 0 & 0 & 0 & 0 & 0 \\
\hline Band48 & 21.382 & 0 & 0 & 0 & 0 & 0 & 0 & 1 & 0 \\
\hline Band49 & 17.678 & 1 & 0 & 0 & 0 & 0 & 0 & 0 & 1 \\
\hline Band50 & 11.689 & 0 & 0 & 0 & 0 & 0 & 0 & 0 & 1 \\
\hline Band51 & 9.946 & 1 & 0 & 0 & 0 & 0 & 0 & 0 & 1 \\
\hline Band52 & 7.750 & 1 & 0 & 0 & 0 & 0 & 0 & 0 & 0 \\
\hline
\end{tabular}




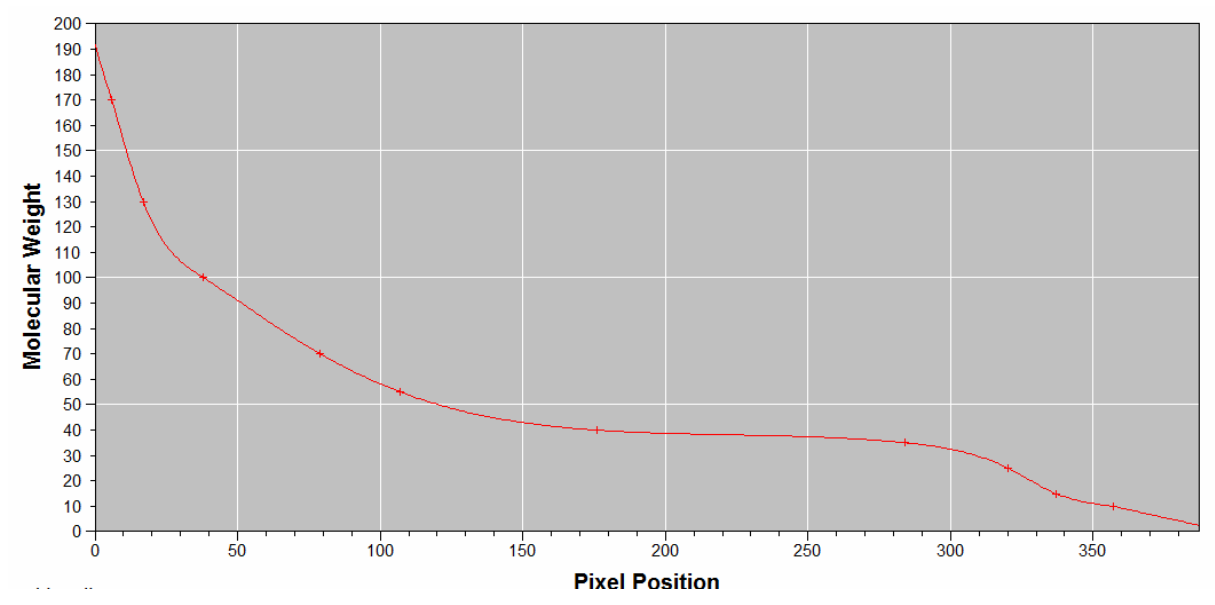

Figure 4. Molecular weight calculation method
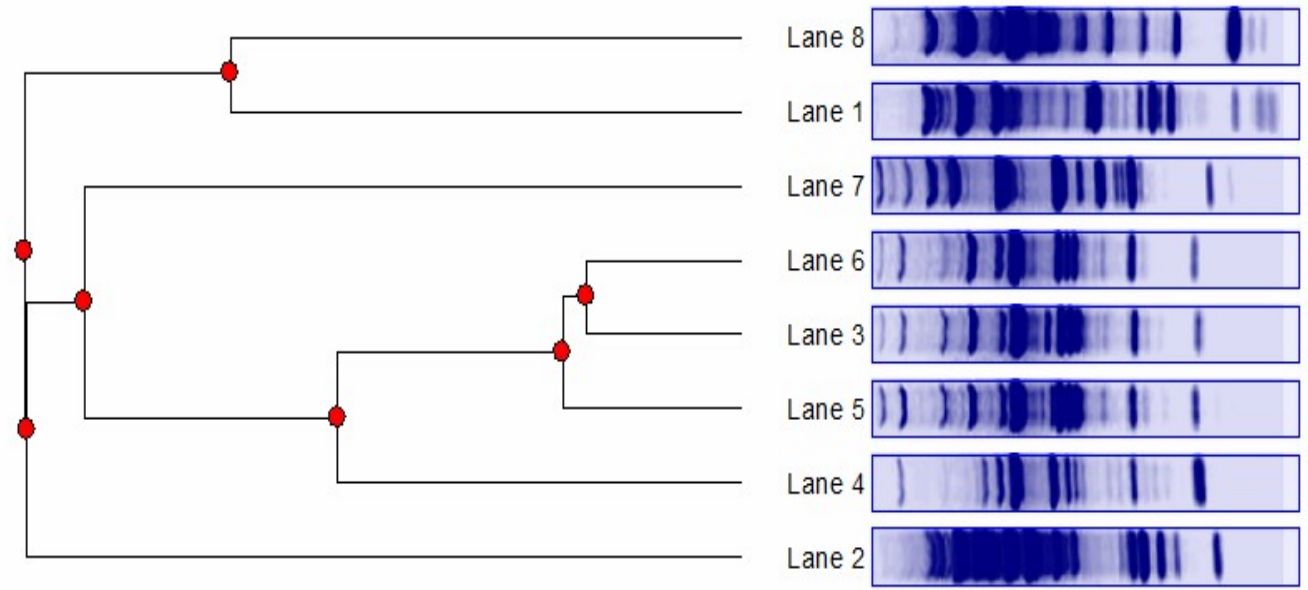

$\begin{array}{lllllll}0.40 & 0.50 & 0.60 & 0.70 & 0.80 & 0.90 & 1.00\end{array}$

Figure 5. Phyllogenetic tree according to SDS-PAGE results 
Table 34.Protein fraction comparision for eight teosinte genotypes

\begin{tabular}{|c|c|c|c|c|c|c|c|c|}
\hline \multirow{2}{*}{ Fractions } & \multicolumn{8}{|c|}{ Teosinte Genotypes protein fractions (KDa) } \\
\hline & 1 & 2 & 3 & 4 & 5 & 6 & 7 & 8 \\
\hline 1 & - & 151 & - & - & 151 & 151 & 151 & - \\
\hline 2 & - & 138 & - & - & - & - & & - \\
\hline 3 & - & & - & - & - & - & 117 & 117 \\
\hline 4 & - & 107 & 107 & 107 & 107 & 107 & - & - \\
\hline 5 & 100 & 100 & & - & - & - & 100 & - \\
\hline 6 & - & - & 94 & - & - & - & & - \\
\hline 7 & 88 & - & & - & - & 88 & 88 & 88 \\
\hline 8 & 81 & 81 & & - & - & - & - & - \\
\hline 9 & 77 & - & 77 & 77 & 77 & 77 & - & - \\
\hline 10 & - & - & - & - & - & - & 73 & - \\
\hline 11 & 69 & 69 & - & - & - & - & & - \\
\hline 12 & 66 & 66 & 66 & - & 66 & 66 & & 66 \\
\hline 13 & - & - & 63 & 63 & 63 & 63 & 63 & 63 \\
\hline 14 & - & 60 & - & & - & - & 60 & - \\
\hline 15 & - & 56 & - & 56 & - & - & - & - \\
\hline 16 & - & - & - & - & 54 & - & - & - \\
\hline 17 & 52 & 52 & - & - & & - & - & 52 \\
\hline 18 & - & - & 50 & 50 & 50 & 50 & 50 & \\
\hline 19 & - & 48 & - & - & - & - & 48 & 48 \\
\hline 20 & 47 & - & 47 & 47 & 47 & 47 & - & 47 \\
\hline 21 & - & - & 45 & - & 45 & 45 & 45 & - \\
\hline 22 & - & 44 & - & - & & 44 & 44 & 44 \\
\hline 23 & 42 & 42 & - & - & 42 & - & - & 42 \\
\hline 24 & 41 & - & 41 & 41 & - & - & - & 41 \\
\hline 25 & & 40 & 40 & - & 40 & 40 & 40 & - \\
\hline 26 & 39.5 & - & 39.5 & 39.5 & 39.5 & 39.5 & - & - \\
\hline 27 & - & 39 & 39 & 39 & 39 & 39 & - & - \\
\hline 28 & - & - & - & 38.5 & - & - & 38.5 & 38.5 \\
\hline 29 & 37.5 & 37.5 & 37.5 & - & - & 37.5 & 37.5 & - \\
\hline 30 & - & - & 37 & & 37 & 37 & - & - \\
\hline 31 & 36.5 & - & - & 36.5 & - & - & - & 36.5 \\
\hline 32 & - & - & - & & - & - & 36 & - \\
\hline 33 & - & 35.5 & - & 35.5 & - & - & 35.5 & - \\
\hline 34 & 35 & - & - & & - & - & - & - \\
\hline 35 & - & 34.5 & 34.5 & 34.5 & 34.5 & 34.5 & 34.5 & - \\
\hline 36 & 34 & 34 & 34 & 34 & 34 & 34 & - & 34 \\
\hline 37 & 33.5 & - & - & & - & - & - & - \\
\hline 38 & - & - & - & 33 & - & - & - & - \\
\hline 39 & - & 32.5 & - & - & - & - & - & - \\
\hline 40 & - & - & - & - & - & - & - & 32 \\
\hline 41 & 31.5 & - & - & - & - & - & - & - \\
\hline 42 & - & 31 & - & - & - & - & - & 31 \\
\hline 43 & - & - & - & - & 29.5 & 29.5 & - & - \\
\hline 44 & - & - & 29 & 29 & - & - & - & - \\
\hline 45 & 28.5 & - & - & - & - & - & - & - \\
\hline 46 & - & - & - & - & - & - & 28 & - \\
\hline 47 & - & 27 & - & - & - & - & - & - \\
\hline 48 & - & - & - & - & - & - & 21 & - \\
\hline 49 & 18 & - & - & - & - & - & - & 18 \\
\hline 50 & - & - & - & - & - & - & - & 12 \\
\hline 51 & 10 & - & - & - & - & - & - & 10 \\
\hline 52 & 8 & - & - & - & - & - & - & \\
\hline
\end{tabular}




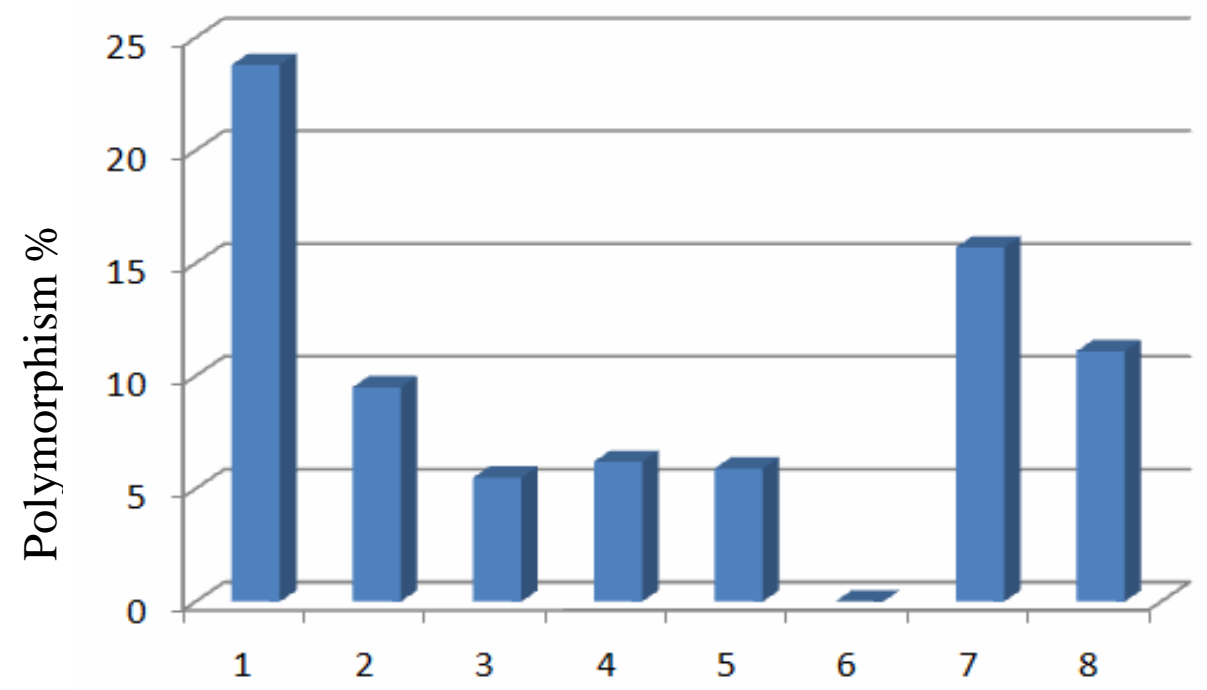

Teosinte genotypes

Figure 6. Polymorphism (\%) for eight teosinte genotypes

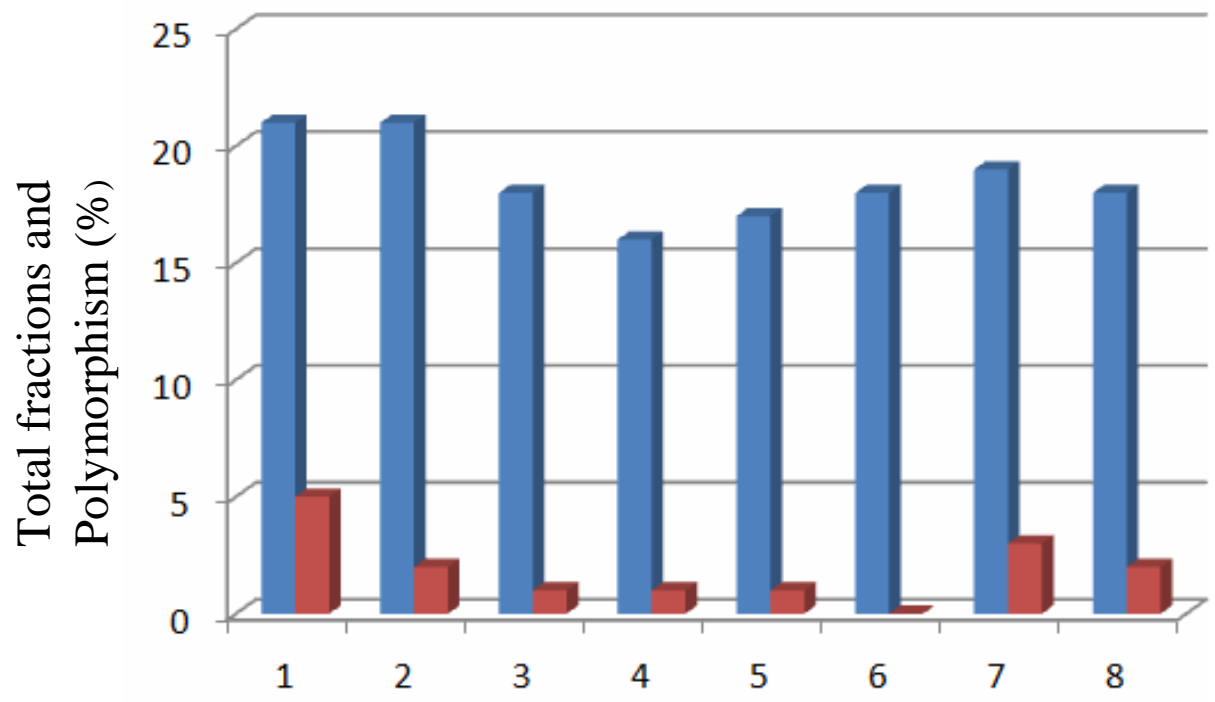

Teosinte genotypes

Figure 7. Total fractions and Polymorphism (\%) for eight teosinte genotypes

Where:

Total fractions

Polymorphism (\%). 
Table 35. Total fractions and polymorphism (\%) for eight teosinte genotypes

\begin{tabular}{ccccc}
\hline Teosinte genotypes & $\begin{array}{c}\text { Total } \\
\text { fractions }\end{array}$ & $\begin{array}{c}\text { Monomorphic } \\
\text { fractions }\end{array}$ & $\begin{array}{c}\text { Polymorphic } \\
\text { fractions }\end{array}$ & Polymorphism (\%) \\
\hline 1 & 21 & 16 & 5 & 23.8 \\
2 & 21 & 19 & 2 & 9.5 \\
3 & 18 & 17 & 1 & 5.5 \\
4 & 16 & 15 & 1 & 6.2 \\
5 & 17 & 16 & 1 & 5.9 \\
6 & 18 & 18 & 0 & 0 \\
7 & 19 & 16 & 3 & 15.7 \\
8 & 18 & 16 & 2 & 11.1 \\
\hline
\end{tabular}

\section{REFERENCES}

Allard, R. W. 1960. Principles of Plant Breeding. Wiley, New York, Alves de Brito. CJFA, R.A.Rodella, F.C. Deschamps and Alquinity. 1999. Anatomia Quantitative Degradacao in Vitro de Cultivares de copim - elefante (Pennisetum Purpureum Schum) Poaceae). Arq. Bio Teanol. (40): $661-671$.

Amos, K.O, K.B Laryea and S. A. Mickson. 2009. Soil water and Nitrogen Interaction Effects on Maize (Zea Mays.) Groun on Vertisol. Journal of Forestry, Horticulture and Science. (3)Issue 1, PP.11.

Aulticino, M. and J. L. Magoja. 1991. Variability and heterosis in Maize - Balsas teosinte and Maize Guatemala teosinte hybrids - Maize Genetics Cooperation Newsletter (on - one Edition). MNL. 65: 43 - 44.

Azab, M.M., E.M.R. Metwali, A.F. Khafaga and E.M. Zayed. 2011. Field Performance and Molecular Profile of Commerical Egyptian Clover (Trifolium alexandrinum L.) varieties under high temperature conditions. Middle. East Journal of Scientific Research 7(5): $652-661$.

Bamdad, S. 2009. Preparation of Slab gel of Structural Proteins Vature. 226: 680-687.

Beadle, G.W. 1977. The Origin of Zea Mays, P. 23-43 in : Reed, C.A., Ed. Origins of Agriculture. 1013P.

Bradford, M.M. 1976. Arapid Sensitive method for the quantification of microgram quantities of protein, Utilizing the Principle of Protein-Dye Binding Analit. Biochem. 72: $248-258$.

De wet, J.M.J., J.R. Harian and C.A. Grant. 1971. Origin and Evaluation of teosinte (Zea Mexicana (Schrad) Kuntze). Euphytica.

20: $255-265$.

Eckebil, J.P., W.M. Ross, C.O. Gardner and J.W. Maranvill. 1977. Heritability Estimates, genetic correlations and predicted gains from SI progeny tests in three grain sorghum random mating populations. Crop Sci. 17: $363-$ 377.

Fedorov, A.A. 1974. Chromosome numbers of flowering Plants. Reprint by Ottokoeltz Science Publishers, Koenigstein, Germany. PP.925.

Frandsen, K.J. 1986. Variability and inheritance of digestibility in perennial ryegrass (Lolium Perenne), Meadow Fescue (Festuca Pratensis) and Cocks foot (Dactylis glomerata): 11. F1 and F2 Progeny. Acta Agric. Sci. 36: $241-263$.
GadEl-Hak, S., H. Mohamoud and R.A. Ragob. 1988. An Evaluation study of Twenty four genotypes of cowpea (Vigna nguiculata (L.) walp) Minia J. Argic. Res. and Dev. 10(1): $257-268$.

Hamdi, A., A.A. El-Ghareib, S.A. Shafey and M.A.M. Ibrahim. 2003. Genetic Variability, Heritability and Expected genetic advance for earliness and seed yield from selection in Lentil. Egypt. J. Agric. Res. 81: 125137.

Harian, H.V. and M.N. Pope. 1922. The use and value of back-crosses in small grain breeding. Journal of Heredity. 13: $319-322$.

Hong, K.S., H.J. Lee and J.H. Rhyu. 1987. Response of Maize and Soybean Canopy Structure, dry matter and Yield to intercropping. Koreenj. Crop sd. 32: 357 - 358 [Field Crops Absts, 42(11): 8562 - 1989].

Katiyar, S.K. and J.K.S. Sachan. 1992. Isozyme diversity in Zea and related genera. Maize Newsetter. (66): 92.

Khatab, I. A., K. R. Moesy, W.M. Fares and T. Kumarn. 2016. Genetic diversity of Soybean genotypes evaluated by Agro - Morphological and SSR markers Plant Breeding. 20 (4):593-608.

Kim, D. A. and S. Seo. 1988. Comparative study of introduced oats for forage production, growth characteristics and yield of spring oats Korean J. Anim. Sci. 30: 269-275.

Knight, A.C., J.S. Price and G.E. Gale. 1996. Mechanical Removal of Surface moisture from grass. Grass Forage Sci. 51: 412-417.

Kumar, M.V.N. and S.S. Kumar. 2000. Studies on Character Association and Path Coefficient for grain Yield and Oil Content in Maize (Zea mays L.) Ann. Agric. Res. 21: 73 78.

Laemmli, U.K. 1970. Cleavage of Structural Proteins during the Assembly of the head of Bacteriophage T4. Vature. 227. (5259): 680-685.

Liu, Y., Y. L. Entaowang and C. Wenxin. 2007. Diverse Bacteria Isolated From Root Nodules of Trifolium. Crotarial. and Mimosa grown in the sub-Tyopical Regions of Chinex Archives of Microbiology. (I) 188: 114.

Manggoel, W. M., I. Uguru., O. N. Ndam And M.A. Dosbak. 2012. Genetic variability, Correlation and Path coefficient analysis of some yield components of ten cowpea (vignava nguiculate (L.) Walp) accessions, journal of plant Breeding and Cropsci. 4: 80 - 86 . 
Muhammad, I.M. R, A. Sultan, M. Akram and M.A. Goheer. 2006. Green Fodder Yield and Quality Evaluation of Maize and Cowpea Sown Alone and In combination. J. Agric. Res. 44: 15-22.

Nawaz, N., A. Z.Razzag And M. Yousuf. 2004. Performance of different oat Varieties under the Agroclimatic conditions of Bahawlapur Pakistan. Int. J. Agric. Bio1. 6: 624-626.

Nwosu, DJ., B.D. Olatunbosum and I.S.Adetilaye. 2013. Genetic Variability Heritability and Genetic Advance in Cowpea Genotypes in two Agroecological Environments Greener Journal of Biological Sci. 3: 202 - 207.

Patrick, C., M.D. Casler, P. Okiely and L.J. Dowley. 2008. Efficiency of Indirect selection for Dry Matter Yield Based on Fresh Matter Yield in Perennial Ryegrass SW and Plots. Crop Sci. 48: 127 - 133.

Rashwan, A. 2010. Estimates of some genetic parameters using six population of two cowpea hybrids. Asian Journal of Crop Sci. 2: $261-266$.
Sammour, R.H. 1994. Seed Protein homology and species relationship in the tribe, Viciea. Feddes Repertorium. 105: $191-196$.

SAS Institute, Inc. 2007. SAS Technical Report AS/STAT Software : Changes and Enhancements User's Guide, Volume 2, Version 9.1.3, Fourth Edition, Cary, NC : SAS Institute, Inc.

Sharma, C.D. and D.L. Sinhania. 1992. Performance of Cowpea (Vigna Ungulculata L. Walp.) Genotypes for fodder traits. Annals of Avid Zoue. 31: 65 - 66.

Srikumar, S.G. and D.I.S Bai. 1995. Genetic analysis of Yield and its components in fodder Maize, Journal of Tropical Agriculture. 33: 8- 10 .

Steel, R.G. and Torrie. 1980. Principles and Procedures of Statistics $2^{\text {nd }}$ ed. Mc Graw Hill, New York, U.S.A.

Sultan, F. M., A. Khalil and S. Salem. 2016. Evaluation of Some cowpea genotypes in Egypt for growth Yield and Quality Traits. Egyptian Journal of Plant Breed. 20(4): 593-608. 


\section{الملخص العربي}

\section{تقييم بعض التراكيب الوراثية المبشرة من الذرة الريانة للصفات المورفولوجية والثوابت الوراثية تحت الظروف المصرية}

هند حبيبة، عبد العزيز طلعت بندق ومحمد عبد العال

وأظهرت تقنية تحليل البروتين SDS - PAGE) التباين

بين التزر اكيب الور اثثية من حيث المحتوى البروتيني الكنـي

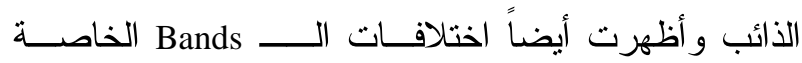

بالبروتين في التر اكيب الور اثثة المدروسة حيث تراوح عدد

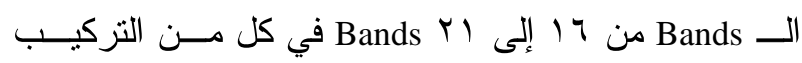
الور اثي رقم (r) و التركيب الور اثي رقم (1) وكذلك النشابه

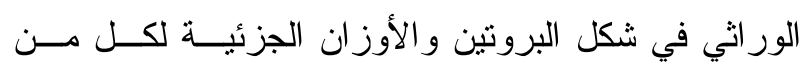

التركيب الور اثي رقم (ץ) و التركيب الور اثي رقم (ع).

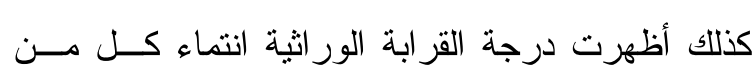

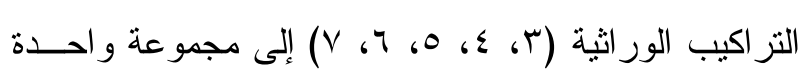

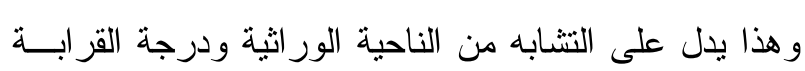

الور اثية بينهم. ولدي

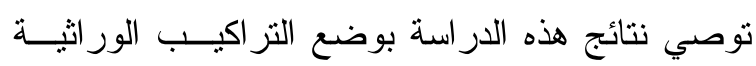

رقمي r و ع كتر اكيب ور اثية مبشرة جديدة من الذرة الريانة تتميز بصفات محصولية علفية جيدة.

الكلمات الدالة : الذرة الريانة - التباين الور اثي - تحليل

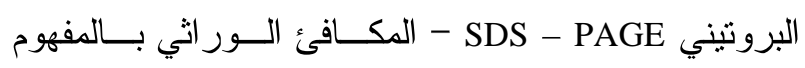

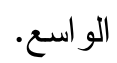

يعتبر تحليل التباين بين التراكيــب الور اثيــــة المختلفــــة


ودرجة التوريث ودرجة القرابة من الأهمية بما كان لنجاح

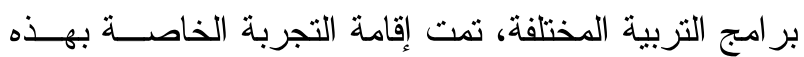

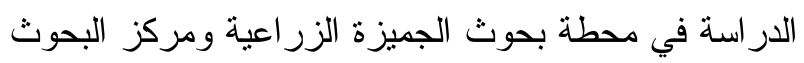

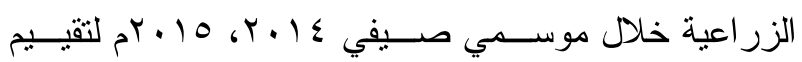

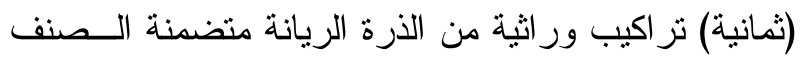

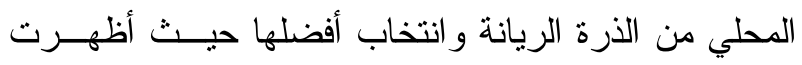

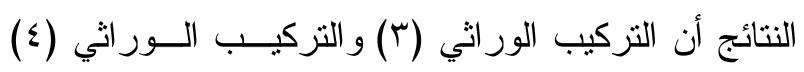

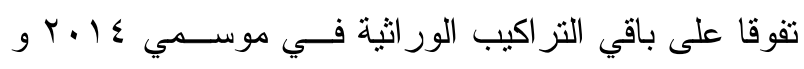

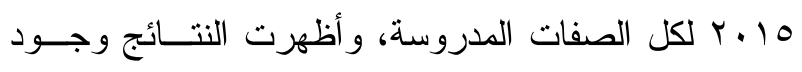

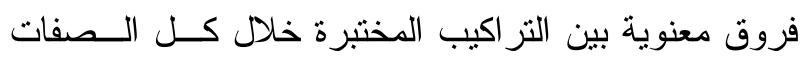

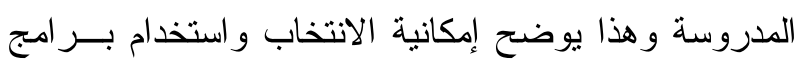

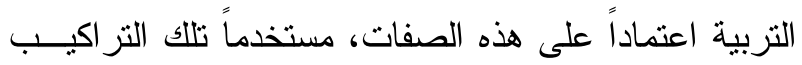

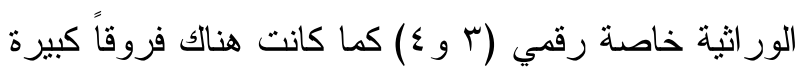

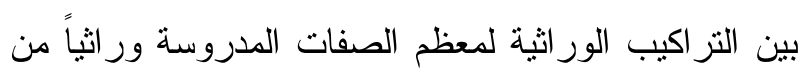
خلال درجة التوريث بمفهومها الواسع حيث أظهرت النتائج



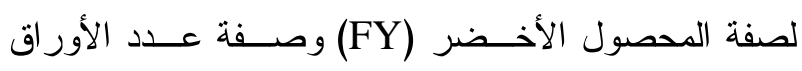
بالساق (NL/S). 